\title{
LA CORTE INTERAMERICANA A CUARENTA AÑOS DE SU ESTABLECIMIENTO'
}

THE INTER-AMERICAN COURT FORTY YEARS AFTER ITS ESTABLISHMENT

SERgIO García RAMÍREZ ${ }^{2}$

RESUMEN: Este artículo ofrece un panorama sobre la creación, el desarrollo y las aportaciones de la Corte Interamericana de Derechos Humanos a la tutela de estos derechos, a través de una jurisprudencia que actualmente comprende la interpretación de la mayoría de los derechos y libertades previstos en la Convención Americana (Pacto de San José). En 2018 se celebra el cuadragésimo aniversario de la vigencia de la Convención, fundamento de la Corte Interamericana. Se alude a la tutela internacional de los derechos humanos y a los antecedentes de la Corte en diversos planteamientos emanados de conferencias de los países americanos, a partir de 1945, 1948 (Novena Conferencia Interamericana), 1959 (establecimiento de la Comisión Interamericana) y 1969 (Conferen-

1 Este texto me fue solicitado con motivo del cuadragésimo aniversario del establecimiento de la Corte Interamericana de Derechos Humanos, por mi apreciado colega Eduardo Ferrer Mac-Gregor, Presidente de ese Tribunal. Los organizadores de la celebración han procurado reunir reflexiones de antiguos juzgadores, con énfasis en hechos y participaciones correspondientes a la etapa de su desempeño. Esto explica las citas y referencias a mis tareas y experiencias como juez (1998-2009) y presidente (2004-2008) de la Corte. Nada más lejos de mi intención que formular una "autobiografía judicial"; sólo he pretendido atender, en sus términos, la invitación que recibí. De mi ingreso a la Corte -alentado por el profesor Héctor Fix-Zamudio- y de mi experiencia en ella he dado cuenta en un artículo intitulado "Mi paso por la Corte Interamericana", incluido en mi libro Para la Navidad del 2017 (México, GVS Publicaciones, 2017, pp. 125 y ss.). Me satisface entregar este texto a la Revista del Posgrado de la Facultad de Derecho de la UNAM.

2 Exjuez y expresidente de la Corte Interamericana de Derechos Humanos. Investigador en el Instituto de Investigaciones Jurídicas y antiguo profesor de la Facultad de Derecho de la Universidad Nacional Autónoma de México. Investigador Emérito del Sistema Nacional de Investigadores (México). 
cia de San José sobre Derechos Humanos). Destaca el carácter vinculante que tiene la interpretación adoptada por la Corte tanto en opiniones consultivas como en sentencias. Por lo que toca a los temas cubiertos por la jurisprudencia de este Tribunal, se menciona la tutela de grupos e individuos vulnerables (tema que el autor denomina "jurisprudencia para los vulnerables"): mujeres, niños, indígenas, discapacitados, pobres, migrantes, desplazados y detenidos. Se agregan otros sectores: periodistas, defensores de derechos humanos y LGBTTI. Igualmente, se alude a la jurisprudencia relativa a reparaciones por hechos ilícitos y acceso a la justicia. El artículo pone énfasis en las observaciones, experiencias y aportaciones del autor como integrante y presidente de la Corte Interamericana.

Palabras clave: Derechos humanos. Sistema Interamericano. Convención Americana sobre Derechos Humanos. Corte Interamericana de Derechos Humanos. Comisión Interamericana de Derechos Humanos. Furisdicción. Furisprudencia. Interpretación. Grupos y personas vulnerables. Acceso a la justicia. Reparación de violaciones a derechos humanos.

ABSTRACT: This article provides an overview of the creation, development and contributions of the Inter-American Court of Human Rights to the protection of these rights through jurisprudence that currently comprises the interpretation of most of the rights and freedoms set forth in the American Convention (Pact of San José). 2018 marks the fortieth anniversary of the entry into force of this Convention, cornerstone of the Inter-American Court. Reference is made to the international protection of human rights and Court precedents on various issues arising from conferences of countries in the Americas held since 1945: 1948 (Ninth InterAmerican Conference), 1959 (creation of the Inter-American Commission) and 1969 (San José Conference on Human Rights). It highlights the binding nature of the interpretation adopted by the Court in both advisory opinions and judgments. As to the issues covered by the case law of this Court, the most significant are the protection of vulnerable groups and individuals (which the author calls "case law for the vulnerable"): women, children, indigenous peoples, the disabled, the poor, migrants, displaced persons and detainees. Other sectors have been added: journalists, human rights defenders and LGBTTIs. Allusions are also made to case law regarding reparation for wrongful acts and access to justice. This article emphasizes the observations, experiences and contributions of the author as a member and president of the Inter-American Court. 
Keywords: Human Rights. Inter-American System. American Convention on Human Rights. Inter-American Court of Human Rights. Inter-American Commission on Human Rights. Jurisdiction. Case law. Interpretation. Vulnerable individuals and groups. Access to justice. Reparation for human rights violations.

SumARIO: I. El alba del Sistema; II. El Tribunal supranacional; III. Sede e itinerancia; IV. La Corte reguladora. Normas y prácticas; V. Interpretación vinculante: hacia un Derecho común; VI. Del orden internacional al orden nacional; VII. Diálogo judicial y control de convencionalidad; VIII. Vocación institucional. La jurisprudencia "transformadora"; IX. El "juez natural" del Sistema. Permanencia y autonomía; X. Integración del Tribunal: nueva interpretación; XI. Los protagonistas; XII. Derechos y libertades, temas de la jurisprudencia; XIII. Una cuestión permanente: acceso a la justicia y debido proceso; XIV. El deber de garantía. Impunidad y violaciones graves; XV. Justiciabilidad de los DESCA; XVI. Vulnerables: jurisprudencia para los más débiles; XVII. Urgencia y gravedad: medidas provisionales; XVIII. Consecuencias jurídicas (reparación): actuar sobre los factores de las violaciones; XIX. Cumplimiento, impacto y trascendencia.

\section{El alba del Sistema}

1 Celebramos el cuadragésimo aniversario del establecimiento de la Corte Interamericana de Derechos Humanos, cuya aparición debió vencer obstáculos y recelos. Y festejamos el septuagésimo aniversario de un hecho germinal para esa jurisdicción: la Declaración Americana de Derechos y Deberes del Hombre, adoptada en Bogotá, en 1948. Para apreciar las vicisitudes que enfrentó el advenimiento de la Declaración regional, conviene recordar el concepto entonces prevaleciente acerca de la soberanía y la jurisdicción doméstica. Además, es preciso evocar la circunstancia regional americana: se trataba de construir un sistema continental novedoso, que abriera el cauce a una estructura que sustituiría a la Unión Panamericana, con todo lo que ello implicaba. Igualmente, es necesario considerar la circunstancia inmediata 
que rodeó a los participantes en la Conferencia de 1948: las dramáticas horas del "Bogotazo". ${ }^{3}$

2. La corriente favorable a la fundación de un Sistema Interamericano protector de los derechos humanos y de una verdadera jurisdicción sobre la materia, emprendió la marcha -sin perjuicio de antecedentes apreciables- en la Conferencia sobre Problemas de la Guerra y de la Paz, conocida como Conferencia de Chapultepec (México, 1945), en honor de la egregia sede que tuvo aquel encuentro de los Estados americanos. La Declaración de 1948 fue adoptada (2 de mayo de 1948) en el Gimnasio Americano de la capital colombiana, varios meses antes de la Declaración Universal (10 de diciembre de 1948). Por lo tanto, corresponde a la regional el honor -y a nosotros, mujeres y hombres de América, la satisfacción- de que aquélla fuese el primer instrumento de su género en la historia de la humanidad. Constituyó la carta de advenimiento del Derecho internacional de los derechos humanos.

3. En su tiempo, la emisión de un instrumento con tales pretensiones remontó criterios tradicionales que opusieron resistencia: un sistema internacional o supranacional que interviniese en cuestiones concernientes a la jurisdicción doméstica quebrantaría las facultades soberanas de los Estados. ${ }^{4}$ Algunos testigos de esa hora advierten sobre la vacilación en ir hacia adelante: tan lejos y tan pronto como se pudiera. ${ }^{5}$ Sin embargo, el propósito de colocar al ser humano en el centro del escenario, sin fronteras territoriales para el reconocimiento y la plena vigencia de su dignidad y de los derechos y libertades inherentes a ésta, venció los escollos y permi-

${ }^{3}$ Cfr. Sergio García Ramírez, La Corte Interamericana de Derechos Humanos, $2^{\mathrm{a}}$. ed., México, Porrúa, 2015, pp. 8-9.

4 Sobre los problemas que debió enfrentar la declaración, en su tiempo y circunstancia, cfr. Carlos García Bauer, Los derechos humanos. Preocupación universal, Guatemala, Universidad de San Carlos, 1960, p. 9

5 Cfr. Eduardo Jiménez de Aréchaga, "Prólogo" a García Bauer, Los derechos humanos..., cit., p. 9 
tió el paso paulatino hacia un Sistema Interamericano, que implicó una transición mayor dentro de la breve historia de la tutela internacional de los derechos humanos. El ser humano reasumió el papel eminente que le reconocieron las declaraciones revolucionarias del siglo XVIII. La marcha se vio abonada, desde luego, por la reacción universal frente al siniestro espectáculo de las grandes guerras.

4. El trabajo preparatorio de la jurisdicción interamericana de los derechos humanos transitó por varios anteproyectos de convención, como el formado por el Consejo Interamericano de Jurisconsultos. Igualmente, le precedió la creación bienhechora de la Comisión Interamericana de Derechos Humanos. Ésta "hizo camino al andar", a partir de la valerosa decisión de los Cancilleres reunidos en Santiago de Chile, en 1959. Pero aún se tendría que remontar, como en efecto ocurrió, las limitaciones contenidas en el primer Estatuto de aquella Comisión. ${ }^{6}$ Luego llegó la Conferencia de San José, en 1969, que adoptó la Convención Americana sobre Derechos Humanos (CADH), incorporando en ella - una vez superadas algunas objeciones, que cedieron en el curso de la Conferencia- a la Corte destinada a interpretar y resolver contiendas a propósito de la aplicación del Pacto de San José, y también a esclarecer consultivamente otros temas del Derecho convencional de los derechos humanos. $^{7}$

6 Cfr. García Bauer, Los derechos humanos..., cit., pp. 153-155. La eficacia de la Comisión, que fortaleció la idea tutelar del Sistema, se mostró en las actuaciones de aquélla en algunos países en que hubo violaciones graves de derechos humanos. Cfr. Thomas Buergenthal y Douglass Cassel, "The future of the Interamerican Human Rights System", en Varios, El futuro del Sistema Interamericano de Protección de los Derechos Humanos, Juan E. Méndez y Francisco Cox (eds.), San José, Instituto Interamericano de Derechos Humanos, 1998, p. 549, y Felipe González Morales, Sistema Interamericano de Derechos Humanos, Valencia, Tirant lo Blanch, 2013, pp. 31 y ss.

7 Sobre la Conferencia de San José, cfr. Conferencia Especializada Interamericana sobre Derechos Humanos, San Fosé, Costa Rica, 7-22 de noviembre de 1969, Actas y Documentos, Secretaría General, Organización de los Estados Americanos, Washington, D.C., rep. 1978. 
5. Pasaría una década antes de que la CADH adquiriese vigencia por ratificación o adhesión de once Estados americanos. Hoy, en 2018, al cabo de otras etapas y contingencias, podemos mirar a nuestra América con el lente de la jurisdicción de los derechos humanos. Por supuesto, este no es el final del camino. Sólo nos encontramos en una estación de lo que he denominado "navegación americana" de los derechos humanos: ${ }^{8}$ a buena distancia del puerto de partida, pero también del punto de llegada -la tierra prometida-, donde tendrán plena vigencia práctica, no sólo discursiva y normativa, los derechos fundamentales del ser humano. Así se habrá trasladado al imperio de la realidad la ferviente utopía de los revolucionarios de América y de Francia, que asignaron a la asociación política -hoy día, la nacional y la internacional- un fin preciso: la protección de los derechos humanos.

\section{iI. El Tribunal supranacional}

6. Quienes aprobaron la creación de una Corte internacional -que califico como supranacional, atendiendo a su propósito y a su eficacia- escucharon las voces que sugerían o reclamaban la presencia de esa jurisdicción al lado de la instancia política que había comenzado a rendir buenos frutos. Esta fue la propuesta de René Casssin,

8 Hay una amplia bibliografía acerca de la etapa inicial del Sistema Interamericano de Protección de los Derechos Humanos. De ésta me he ocupado en mi libro La Corte Interamericana..., cit., pp. 6 y ss. y 100 y ss. Sobre los días del "Bogotazo", cfr. la narración del jefe de la Delegación mexicana y Canciller de su país, Jaime Torres Bodet, en La victoria sin alas, México, Fundación Miguel Al emán, 2012, pp. 273 y ss.

Así, por ejemplo, en "La navegación americana de los derechos humanos: hacia un ius commune", en Varios, Ius constitutionale commune en América Latina. Rasgos, potencialidades y desafios, Armin von Bogdandy, Héctor Fix-Fierro y Mariela Morales Antoniazzi (coords.), México, Instituto Max Planck/UNAM, Instituto de Investigaciones Jurídicas, 2014, pp. 459 y ss. 
invitado a la Conferencia, ${ }^{9}$ además de que lo fuera de un vigoroso conjunto de juristas americanos a los que se debe el progreso de la tutela internacional de los derechos humanos en nuestro continente, entre ellos - participantes o no en el encuentro de San José- Carlos García Bauer y Eduardo Jiménez de Aréchaga.

7. Conscientes de que sería necesario atraer más voluntades y aguardar con prudencia y paciencia el retiro de las piedras que habría en el camino, los suscriptores de la Convención alojaron en ésta una cláusula facultativa sobre la competencia del Tribunal para conocer asuntos contenciosos. ${ }^{10}$ Gradualmente han llegado las adhesiones de los Estados a esa competencia prevista en la CADH. Pero aún son muchos los ausentes tanto del Pacto de San José como del reconocimiento de la competencia sobre asuntos contenciosos.

8. En 1978 entró en vigor la Convención. Con ella, la Corte Interamericana adquirió cuerpo y misión. En la ceremonia de instalación desarrollada en el Teatro Nacional de San José intervinieron varios promotores, defensores y actores de la jurisdicción emergente. El Presidente de Costa Rica, Rodrigo Carazo, señaló que el nuevo Tribunal debía emitir la jurisprudencia que permitiese alcanzar los objetivos del Pacto y aplicar sus disposiciones a plenitud, ${ }^{11}$ iluminando zonas oscuras o indefinidas de la normativa

9 En San José, Cassin señaló "Esta Conferencia tiene un carácter jurídico, casi judicial muy pronunciado". Cotejó las experiencias europea y americana, elogió el progreso significativo alcanzado por la Comisión Interamericana, se refirió a las aspiraciones de algunos países del hemisferio e invitó a "establecer, sin destruir un mecanismo ya probado (la Comisión y su desempeño), un instrumento nuevo que pueda, como en el caso de Europa, reforzar una Convención mediante una serie de interpretaciones y formar una jurisprudencia de valor inapreciable para prevenir violaciones futuras". Conferencia Especializada Interamericana..., cit., p. 434.

10 Sobre este punto y, en general, acerca de las preocupaciones de los autores de la Convención para atraer la voluntad de los Estados, cfr. Amaya Úbeda de Torres, Democracia y derechos humanos en Europa y en América. Estudio de los sistemas europeo e interamericano de protección de los derechos humanos, Madrid, Reus, 2007.

11 Cfr. "Discurso pronunciado por el Excelentísimo señor Presidente de la República de Costa Rica, Lic. Rodrigo Carazo Odio, en el Teatro Nacional de Costa 
e integrando así el sistema de protección de derechos humanos. A éste llegaron las aportaciones de la Corte, inicialmente reunidas en opiniones consultivas - simiente de la jurisprudencia venidera- y posteriormente expuestas, además, en un apreciable número de resoluciones jurisdiccionales de otra naturaleza. En todas ellas se expresan las facultades jurisdiccionales de la Corte: consultiva, contenciosa, preventiva y ejecutiva.

\section{Sede e itinerancia}

9. La jurisdicción interamericana, que tiene sede en San José, Costa Rica-merced a un convenio hospitalario con el gobierno de esa República-, recibió un nuevo impulso fecundo gracias a una decisión insólita: la celebración de períodos de sesiones fuera de la sede regular, acordada en la etapa en que presidí la Corte. Esta práctica, con algunos antecedentes en actuaciones procesales externas (por ejemplo, sesiones relativas a la Opinión Consultiva-18/03, en Santiago de Chile), inició en 2005. A la luz de los buenos resultados obtenidos, se llevó adelante la primera serie de sesiones con audiencias públicas en otros Estados americanos.

10. Me referí a este proyecto en los informes que expuse, como Presidente de la Corte, ante la Comisión de Asuntos Jurídicos y Políticos de la OEA en 2004 y 2005. En el correspondiente a este último año anuncié que el Tribunal desarrollaría un periodo de sesiones, con características novedosas, en la ciudad de Asunción, Paraguay. Aclaré que "no se trata(ría), en modo alguno, de realizar visitas in loco, que conciernen a la Comisión Interamericana, sino de actuaciones jurisdiccionales, especialmente audiencias públicas, que son la materia precisa y estricta del quehacer de la Corte, en la

Rica, el día 3 de septiembre de 1979, con motivo de la instalación de la Corte Interamericana de Derechos Humanos", en Corte Interamericana de Derechos Humanos, Memoria de la Instalación, Secretaría de la CorteIDH/Unión Europea, San José, 1999, pp. 20-21. 
que ésta debe concentrar su atención y dedicación y a la que debe dirigir sus limitados recursos". ${ }^{12}$

11. Tampoco se buscaba, es obvio, dar a la administración de justicia un carácter espectacular, con el peligro, tan sabido, de constituir la justicia en espectáculo. El proyecto, cuidadosamente preparado, conjuró estos riesgos y mostró notables ventajas. En la etapa en que tuve el honor de presidir la Corte, ésta celebró sesiones externas en Asunción, como acabo de indicar, y en Brasilia, Buenos Aires, San Salvador, Guatemala y Bogotá. ${ }^{13}$ En los siguientes años continuó y arraigó este programa, que ha favorecido el conocimiento del Tribunal en los Estados de nuestra región.

\section{iv. La Corte reguladora. Normas y prácticas}

12. La Corte Interamericana posee atribuciones convencionales normativas, administrativas y jurisdiccionales. En seguida me referiré a las normativas, que se deducen del Pacto de San José, secundado por el Estatuto del Tribunal -emitido por la Asamblea General de la Organización de los Estados Americanos-, y por el

12 Consejo Permanente de la Organización de los Estados Americanos, Comisión de Asuntos Jurídicos y Políticos, Sintesis del Informe Anual de la Corte Interamericana de Derechos Humanos correspondiente al ejercicio del año 2004, OEA/Ser.G, CP/ CAJP/INF.19/05, 10 mayo 2005, p. 8.

Sobre este desarrollo en la actividad de la Corte, al que me referí en informes ante la Comisión de Asuntos Jurídicos y Políticos y la Asamblea General de la OEA, cfr. mis referencias en La Corte Interamericana..., cit., pp. 161-163 y 191 y ss, obra en la que también recojo las intervenciones que tuve como Presidente del Tribunal en las ciudades sede de los periodos externos. Igualmente, cfr. Pablo Saavedra y Gabriela Pacheco Arias, "Las sesiones 'itinerantes' de la Corte Interamericana de Derechos Humanos: un largo y fecundo caminar por América", en Varios, Recepción nacional del Derecho internacional de los derechos humanos y admisión de la competencia contenciosa de la Corte Interamericana, García Ramírez y Mireya Castañeda (coords.), México, Secretaría de Relaciones Exteriores/ UNAM, Instituto de Investigaciones Jurídicas, 2009, pp. 37 y ss.

13 Cfr. García Ramírez, La Corte Interamericana..., cit., pp. 191-231. 
Reglamento, cuya elaboración compete a la Corte misma. Éste es mucho más que una regulación interna, protocolo de organización y tramitación: constituye un ordenamiento procesal que rige el despliegue de las competencias jurisdiccionales. En otros términos, el reglamento es un compacto código de procedimientos al que se disciplina la actuación del Tribunal, de la Comisión Interamericana y de los Estados parte en la Carta de la OEA - por lo que toca a las opiniones consultivas-, así como de todos los sujetos que actúan bajo la competencia consultiva o contenciosa de aquél.

13. Las fuentes para la regulación del procedimiento son los acuerdos o determinaciones de la Corte a través de sentencias u opiniones y los procesos de reforma directa a cargo del Tribunal. En los últimos lustros -y, en ellos, la etapa en que tuve el honor de integrar la Corte o de presidirla- se llevó adelante la reforma al Reglamento en consulta con los actores del Sistema acerca de los aspectos sobresalientes para el despacho de su jurisdicción. Esto permitió recibir puntos de vista atentos a los problemas advertidos y a sus posibles soluciones. Así hallaron fundamento varias modificaciones reglamentarias basadas en la experiencia del propio Tribunal o en las aportaciones de los actores del Sistema, señaladamente los Estados, la Comisión Interamericana y las organizaciones de la sociedad civil. El método utilizado - con diseño "democrático", se destacó en algún momento--, sustentó la reforma de 2009, como indica la correspondiente "Exposición de Motivos". ${ }^{14}$

14. Por supuesto, no basta la modificación de normas si ésta no se acompaña con el desarrollo de las prácticas que requiere la actividad jurisdiccional. Es preciso conciliar-sin sacrificio para nadie- la excelencia en la decisión con la diligencia en emitirla. Esto supone

14 Véase la "Exposición de Motivos de la Reforma Reglamentaria" (de 20082009), en Corte Interamericana de Derechos Humanos, Documentos básicos en materia de derechos humanos en el Sistema Interamericano (actualizado a febrero de 2010), Secretaría de la CorteIDH, San José, 2010, pp. 193 y ss. También disponible en: <http://www.corteidh.or.cr/sitios/reglamento/nov_2009_motivos_esp.pdf>. 
retos, como se suele decir, e incorporación de nuevas prácticas. Se procuró hacerlo en la etapa a la que corresponde la mayoría de las referencias contenidas en este texto, como quedó dicho en un informe ante la OEA. ${ }^{15}$

15. La actuación de la Corte debe ser difundida a escalas nacional, regional y mundial. Es importante -más aún, indispensable- que el desempeño del Tribunal y su jurisprudencia sean ampliamente conocidos y analizados, y para ello es preciso utilizar todos los medios disponibles. La publicación de cuadernos sobre opiniones y casos es uno de esos medios, tradicionalmente utilizado -y muy valioso- para atender a ese propósito, como lo es la edición de textos diversos en los que se informa acerca del Tribunal y las tareas que cumple. A estas vías de información se agregó, en mi etapa como Presidente del Tribunal, el relanzamiento de la página web, ${ }^{16}$ que tiempo después adquiriría notable vuelo y se convertiría en un espacio de obligada consulta para quienes se interesan en la tutela interamericana de los derechos humanos, ahora expuesta igualmente por medio de la transmisión electrónica de las sesiones públicas de la Corte. En esa página se recogieron todos los documentos que figuran en los expedientes de casos cerrados, para conocimiento de quienes deseen consultar sin restricciones las piezas que los integran. ${ }^{17} \mathrm{En}$ el tiempo al que se refiere este artículo se alentó igualmente - como se había hecho en etapas anteriores- la

15 A este respecto, en el informe que presenté en 2004 ante la Comisión de Asuntos Jurídicos y Políticos y ante la Asamblea General de la OEA, como Presidente de Corte Interamericana, manifesté que este Tribunal se proponía "ampliar la duración de los periodos de sesiones, reprogramar los trabajos del Pleno de la Corte y de sus integrantes, utilizar más tiempo antes de las reuniones en San José para el estudio y la preparación de casos, buscar nuevas fuentes de financiamiento de algunas actividades y redistribuir, en la medida de lo posible, los recursos disponibles". En el periodo comprendido entre 2004 y 2007, "estas propuestas se convirtieron en hechos, sin salvedad”. La Corte Interamericana..., cit., p. 158.

16 Cfr. ibidem, p. 175.

17 Cfr. idem 
aparición de obras que recogiesen la historia, las funciones y los alcances del Tribunal. ${ }^{18}$

\section{InTERPRETACión Vinculante: HACIA UN DERECHO COMÚN (IUS COMMUNE)}

16. Con paso firme, venciendo asedios de diversa procedencia y aplicando con eficacia sus escasos recursos financieros -merced a la excelencia de sus recursos humanos-, la Corte ha adquirido madurez y prestigio. En efecto, se ha logrado en apreciable medida que las decisiones judiciales posean la virtud que deben tener: trascendencia, que es mucho más que cumplimiento e impacto. La trascendencia es capacidad de mover el derecho interno y, con él, las prácticas domésticas. Implica creciente -aunque no siempre inmediata, fulminante--, recepción de los criterios sustentados en la jurisprudencia del Tribunal.

17. La Corte ha sostenido que la jurisprudencia concurre a integrar la norma tutelar de los derechos humanos, compuesta por las disposiciones textuales de la Convención y por la interpretación que aporta ese Tribunal, su intérprete supremo. Tal es la norma tutelar que informa constituciones, leyes ordinarias, políticas públicas, resoluciones jurisdiccionales y otros actos de los Estados nacionales, merced al esfuerzo de recepción que ha cundido en muchos ámbitos. De nueva cuenta señalo: estamos lejos de llegar al punto de arribo. Cuando se analiza el "cumplimiento de sentencias" hay espacios colmados de sombras, pero también luces que antes no existían. Digámoslo con justicia para quienes las han encendido. ${ }^{19}$

18 Tuvo especial importancia una obra analítica y colectiva que reunió estudios formulados por los jueces integrantes de la Corte y dio cuenta de la jurisprudencia emitida hasta 2004, con índices temáticos: Varios, La Corte Interamericana de Derechos Humanos. Un cuarto de siglo: 1979-2004, CorteIDH, San José, 2005.

19 En mis informes ante la OEA, como Presidente de la CorteIDH, hice notar los avances en el cumplimiento (que ahora identifico bajo el rubro de "trascen- 
18. El Tribunal también ha reiterado que sus resoluciones son vinculantes para los Estados que acogen la Convención Americana. El reconocimiento de esta calidad por parte de la Corte y de los Estados es un factor determinante para el arraigo y la fortaleza de la jurisdicción interamericana. Ha sido relevante sostener la eficacia inter partes de las decisiones judiciales, eficacia que la CADH proclama y que asumen explícitamente los suscriptores de ésta, pero más lo ha sido sostener el imperio erga omnes de la interpretación que hace el Tribunal con respecto a los instrumentos que le confieren competencia ratione materiae. En otros términos, a la cosa juzgada se agrega la "cosa interpretada", como señalan algunos estudiosos, o la interpretación vinculante, como prefiero decir. ${ }^{20}$

19. Ese avance en relación con la fuerza de las sentencias -y de las decisiones en torno a medidas provisionales y cumplimiento de resoluciones- se ha extendido últimamente para comprender los criterios sostenidos por la Corte en sus opiniones consultivas. En un tiempo, la doctrina se dividió y la Corte no reconoció eficacia vinculante a sus opiniones consultivas. Esto ha cambiado, acertada-

dencia" de las resoluciones de aquel Tribunal): “(l)os criterios interpretativos de la Convención incorporados en dichas resoluciones han informado, cada vez más, modificaciones de leyes -inclusive de la más alta jerarquía-, expedición de normas, nuevos rumbos jurisprudenciales, cambios reglamentarios, variación de prácticas". García Ramírez, La Corte Interamericana..., cit., p. 169. También es preciso distinguir los criterios de ponderación del cumplimiento: como observancia de los puntos de condena (en ocasiones muy numerosos) contenidos en las sentencias, o como medición que se cifra en la fórmula "todo o nada". A este respecto, Cfr. Varios, Eficacia del Sistema Interamericano de Derechos Humanos, Bogotá, Universidad Católica de Colombia, 2015, pp. 34-35. Los informes que rendí ante la OEA se encuentran disponibles en: <http://www.corteidh.or.cr/informe-anual.html>.

${ }^{20}$ Cfr. García Ramírez y Claudio Zanghi, "Las jurisdicciones regionales de derechos humanos y las reparaciones y efectos de las sentencias", en Varios, $E l$ diálogo entre los sistemas europeo y americano de derechos humanos, Raúl Canosa Usera, Javier García Roca, Pablo Santolaya y Pablo Antonio Fernández (coords.), $2^{a}$.ed., Lima, Thomson Reuters, 2015, pp. 460-461. 
mente, a partir de la $O C-21 .^{21}$ Los Estados parte en la Convención -y en otros tratados del ámbito americano- se obligan a dar cumplimiento a las normas sustantivas contenidas en esos instrumentos, que se incorporan a su propio orden jurídico. Y el alcance de esos preceptos se halla definido, en último examen, por la jurisprudencia de la Corte Interamericana, intérprete de la Convención y de aquellos tratados. De ahí que sea vinculante la interpretación provista por ese Tribunal, que concurre a integrar la norma cuya observancia es obligatoria, tanto en las opiniones como en las sentencias. Considero que está pendiente el examen de la eficacia de las opiniones consultivas sobre tratados que no forman parte del sistema normativo americano, pero son aplicables en países de América, tratados que también figuran en la competencia consultiva del Tribunal de San José.

Vi. Del orden internacional AL ORDEN NACIONAL

20. Los Estados han emprendido la construcción de vías de acceso del Derecho interamericano al orden interno. Lo hacen a través de los que suelo denominar "puentes": constitucional, legal, político, jurisdiccional y cultural. ${ }^{22}$ Así se plantea y acredita la trascendencia de las decisiones de la Corte. Ha caminado hacia adelante el acatamiento a las decisiones de aquélla, andando sobre un terreno difícil, accidentado, en el que aparecen obstáculos previsibles o imprevistos.

21. En los últimos lustros $-\mathrm{y}$ claramente en la etapa de la que guardo memoria como juez del Tribunal de San José- la gran ma-

21 Cfr. $O C$-21/14, "Derechos y garantías de niñas y niños en el contexto de la migración y/o en necesidad de protección internacional”, párrs. 31-32.

22 Cfr. mi desarrollo de esta idea, marco para la recepción del Derecho internacional de los derechos humanos en el orden jurídico interno, en "Relación entre la jurisdicción interamericana y los Estados (sistemas nacionales). Algunas cuestiones relevantes", en La Corte Interamericana..., cit., pp. 685. 
yoría de los Estados expresó su convicción de cumplimiento de las decisiones de la Corte. Se expresó en resoluciones de las altas cortes nacionales y de otros tribunales domésticos. ${ }^{23}$ Alguna vez se afirmó la decisión de acatamiento, a pesar de que el tribunal interno no compartía los razonamientos y las conclusiones del Tribunal de San José. ${ }^{24}$ Sin embargo, esa recepción es inestable. Hubo en el pasado -fuertemente- y se han reproducido en el presente reticencias o reservas que ponen en entredicho la fuerza de la jurisprudencia interamericana, buscando sustraerse a ella o sujetarla a apreciaciones de instancias nacionales. ${ }^{25}$ Es preciso mantener la atención en vigilia; estos peligros pudieran multiplicarse y mellar la integridad del Sistema Interamericano.

\section{Vil. Diálogo Judicial y CONTROL DE CONVENCIONALIDAD}

22. Existe una fuerte relación entre los órganos jurisdiccionales internos y la Corte Interamericana, que se describe bajo el expresivo concepto de "diálogo jurisprudencial". Prefiero hablar de "diálogo jurisdiccional”, puesto que la comunicación y sus consecuencias no ocurren apenas entre los productos de la jurisdicción, la jurisprudencia, sino a partir de la función misma de los órganos

23 Cfr. Gomes Lundy otros ("Guerrilha do Araguaia") vs. Brasil, 24 de noviembre de 2010, párrs. 163-169, y Cabrera García y Montiel Flores vs. México, 26 de noviembre de 2010, párrs. 225-232.

24 Cfr. Bulacio vs. Argentina, Supervisión de Cumplimiento de Sentencia, Resolución de la Corte Interamericana de Derechos Humanos de 26 de noviembre de 2008, párrs. 8-11, y Corte Suprema de Justicia de la Nación (Argentina), Espósito, Miguel Ángel s/ incidente de prescripción de la acción penal promovido por su defensa, 23 de diciembre de 2004, párr. 12.

25 De mi etapa como juzgador puedo citar la decisión adoptada por el Gobierno de Perú, rechazada por la CorteIDH y luego retirada por el Estado. Cfr. "Una controversia sobre la competencia de la Corte Interamericana de Derechos Humanos", en García Ramírez, La jurisdicción internacional. Derechos humanos y justicia penal, México, Porrúa, 2003, pp. 269 y ss. Asimismo, en mi libro Estudios jurídicos, México, UNAM, Instituto de Investigaciones Jurídicas, 2000, pp. 389 y ss. 
internacional y nacionales que participan conjunta y deliberadamente en la formación de un derecho común americano, idea que ha ganado fuerza - no sin cuestionamientos- y que forma parte de las ocupaciones actuales de muchos estudiosos y actores del Sistema Interamericano.

23. En otra época, ciertamente no remota - porque nada lo es en la corta historia del Sistema-, los órganos jurisdiccionales locales e internacional caminaron distanciados. Aquellos atendían escasamente las orientaciones de la justicia internacional, y ésta no acogía los criterios acuñados en la doméstica. Obviamente, la desatención nacional al régimen supranacional gravitaba desfavorablemente en la tutela internacional de los derechos humanos y empobrecía la tutela nacional en perjuicio de los ciudadanos. La situación cambió en las décadas más recientes, y se abrió el horizonte para ambos órdenes jurisdiccionales, primero a través de intercambios en foros políticos o académicos, que facilitaron el conocimiento mutuo y generaron confianza entre los interlocutores, y luego mediante la franca aceptación doméstica de la jurisprudencia interamericana. Esto confirió sentido y vigor al "diálogo jurisdiccional", como fragua para la asunción compartida de razones y orientaciones, que culminan en el Derecho común interamericano. Tuve la fortuna de participar en este proceso de gradual aproximación, expresado - por ejemplo- en reuniones de tribunales en Punta del Este, Uruguay, ${ }^{26}$ y en Guernavaca, México. ${ }^{27}$

24. Posee gran relevancia el control de convencionalidad, tema que se halla en nuestro constante escenario. Hace más de quince años me referí a la existencia de un control de "internacionalidad"

26 XII Encuentro Anual de Presidentes y Magistrados de Tribunales, Cortes y Salas Constitucionales de América Latina, Punta del Este, 2005. Cfr. <https:// www.scjn.gob.mx/relaciones-institucionales/encuentro-anual>.

27 XIII Encuentro Anual de Presidentes y Magistrados de Tribunales, Cortes y Salas Constitucionales de América Latina, Cuernavaca, 2006. Cfr. <https:// www.scjn.gob.mx/relaciones-institucionales/encuentro-anual>. 
o de "juridicidad" - a la manera del control de constitucionalidadderivado de la comunidad entre los objetivos del orden interno informado por convicciones humanistas y democráticas, y el internacional sustentado en las mismas convicciones. ${ }^{28} \mathrm{~A}$ la reflexión sobre esta coincidencia se agregó el reconocimiento de que las disposiciones del Derecho internacional de los derechos humanos y las decisiones interpretativas y aplicativas de la Corte Interamericana no se dirigen apenas a cierto sector del Estado nacional, sino deben ser atendidas por éste en su conjunto, lo que entraña una obligación ineludible a cargo de los tribunales domésticos. En mi voto concurrente a la sentencia del caso Myrna Mack Chang (Guatemala) aludí al "control de convencionalidad" por parte de la Corte lnteramericana. ${ }^{29}$

25. El Tribunal de San José asumió y desarrolló la doctrina del control de convencionalidad como atribución - facultad y deber- de los tribunales nacionales, tema que ha cundido y originado importantes consecuencias. Un notable paso en esta dirección, en el que participé como miembro de la Corte, se produjo en la sentencia del caso Almonacid. ${ }^{30}$ Esta es una de las más valiosas aportaciones de la Corte Interamericana al desarrollo del Sistema. Del control a cargo de los juzgadores, como renovada expresión de las atribuciones naturales de éstos, se transitó al control a cargo de órganos o funcionarios auxiliares de la justicia, y más tarde al control por parte de todos los agentes del Estado, lo cual implica una especie de control universal por un gran número -millares o millones- de

28 Cfr. García Ramírez, Temas de derecho, México, Universidad Autónoma del Estado de México/Seminario de Cultura Mexicana/UNAM, Instituto de Investigaciones Jurídicas, 2002, p. 435.

29 Cfr. García Ramírez, Votos particulares en la Corte Interamericana de Derechos Humanos y reflexiones sobre el control de convencionalidad, $2^{\mathrm{a}}$. ed., México, GNDH, 2015, pp. 210-211, y <http://www.corteidh.or.cr/docs/casos/articulos/seriec_101_esp. pdf>.

30 Cfr. Almonacid Arellano y otros vs. Chile, 26 de septiembre de 2006, párr. 124. 
agentes públicos, con o sin investidura judicial. Otro punto relevante, que requiere análisis, es el relativo a los efectos del control y a los presupuestos de éste. ${ }^{31}$

26. Creo que sería útil una nueva consideración de la materia, tomando en cuenta los fines últimos del control, su mejor operación

31 Sobre el origen de la doctrina del control de convencionalidad en la CorteIDH, cfr. Giuseppe de Vergottini, Más allá del diálogo entre tribunales, comparación y relación entre jurisdicciones, trad. de Pedro J. Tenorio Sánchez, Pamplona, Civitas-Thomson Reuters, 2010, p. 112; Ernesto Rey Cantor, Control de convencionalidad de las leyes y derechos humanos, México, Porrúa, 2008, pp. 46 y 167-171; Juan Carlos Hitters, "Control de constitucionalidad y control de convencionalidad. Comparación”, en La Ley, Buenos Aires, 2009, pp. 1-5; Néstor Pedro Sagüés, "El control de convencionalidad como instrumento para la elaboración de un ius commune interamericano", en Varios, La justicia constitucional y su internacionalización. ¿Hacia un ius constitucionale commune en América Latina?, Armin von Bogdandy, Eduardo Ferrer Mac-Gregor Poisot y Mariela Morales Antoniazzi (coords.), México, UNAM, Instituto de Investigaciones Jurídicas/ Instituto Max Planck/ Instituto Iberoamericano de Derecho Constitucional, t. II, 2010, p. 449, "El control de convencionalidad en el Sistema Interamericano y sus anticipos en el ámbito de los derechos económico-sociales. Concordancias y diferencias con el Sistema Europeo”, en Varios, El control difuso de convencionalidad. Diálogo entre la Corte Interamericana de Derechos Humanos y los jueces nacionales, Eduardo Ferrer Mac-Gregor Poisot (coord.), México, FUNDAP, 2012, p. 422, y La interpretación judicial de la Constitución. De la constitución nacional a la constitución convencionalizada, México, Porrúa, 2013, pp. 344-346; Allan R. Brewer-Carías y Jaime Orlando Santofimio Gamboa, Control de convencionalidad y responsabilidad del Estado, Bogotá, Universidad Externado de Colombia, 2013, p. 47; Eduardo Ferrer Mac-Gregor, "Interpretación conforme y control difuso de convencionalidad. El nuevo paradigma para el juez mexicano", en Varios, El control difuso..., cit., pp. 132-133; Víctor Bazán, "Estimulando sinergias: de diálogos jurisprudenciales y control de convencionalidad", en Varios, El control difuso..., cit., pp. 15 y ss.; Carlos Ayala Corao, Del diálogo jurisprudencial al control de convencionalidad, Caracas, 2012, pp. 133 y ss., 142 y 147; José Luis Caballero Ochoa, La interpretación conforme. El modelo constitucional ante los tratados internacionales sobre derechos humanos y el control de convencionalidad, México, Porrúa, 2013, pp. 75-76, y Emmanuel Rosales, "En busca del acorde perdido o la necesidad de un lenguaje común para el análisis sistemático de la aplicación del Derecho internacional de derechos humanos por cortes nacionales", en Varios, El control de convencionalidad y las cortes nacionales. La perspectiva de los jueces mexicanos, Paula M. García Villegas Sánchez Cordero (coord.), México, Porrúa, 2013, p. 180. 
y el propósito - destacado por varios juristas- de utilizarlo como medio para la formación del derecho común. ${ }^{32}$ En todo caso, el concepto mismo de control -que primero es subordinación al orden internacional convencional, y luego confrontación entre éste y el orden interno- ha sido un asunto descollante en la doctrina reciente de la Corte Interamericana y en la meditación y actuación de juzgadores y académicos.

VIII. VOCACIÓN INSTITUCIONAL. LA JURISPRUDENCIA "TRANSFORMADORA"

27. En diversas ocasiones he subrayado lo que caracterizo como "vocación institucional" de la Corte Interamericana. ${ }^{33}$ Desde luego, todos los tribunales comparten una vocación justiciera y enfilan sus tareas en el sentido que ordenan las disposiciones que los gobiernan. La Corte Interamericana posee esa misma vocación genérica y la asume en los términos de la circunstancia en la que actúa y de la misión específica que tiene. No es una instancia para el conocimiento de gran número de casos; no puede actuar y no actúa con este propósito; tampoco pretende ser -lo ha desechado expresamente- un tribunal de última instancia para revisar los litigios domésticos. Se ha comprometido con la causa de los derechos humanos y trabaja para la trascendencia de sus resoluciones como factor de profunda reforma inmediata o mediata, a sabiendas

32 Cfr. Sagües, La Constitución bajo tensión, Querétaro, Instituto de Estudios Constitucionales, 2016, p. 417.

33 Cfr. "Relación entre la jurisdicción interamericana y los Estados (sistemas nacionales). Algunas cuestiones relevantes", en La Corte Interamericana..., cit., pp. 684-685, y Reunión de expertos sobre el Sistema Interamericano de Derechos Humanos, Center for Civil and Human Rights, Indiana, University of Notre Dame, Estados Unidos de América, 31 de marzo-2 de abril de 2014, disponible en: <https://humanrights.nd.edu/assets/134036/garciaramireziaspan.pdf>. 
de que esta empresa magna no se consuma en un día ni depende -subrayémoslo- solamente de la tarea jurisdiccional.

28. Las resoluciones de la Corte Interamericana tienen naturaleza y pretensión "transformadora". Calan en los factores de la violación de los derechos y alientan la garantía de no repetición. Exploran el contexto de los hechos violatorios, identifican su gestación remota o cercana y previenen su persistencia o multiplicación futura. Esta aspiración explica el carácter de muchas sentencias del Tribunal en aspectos básicos de su mejor jurisprudencia: así, las consecuencias de la violación de derechos humanos, generalmente identificadas como reparaciones, y las decisiones, cada vez más frecuentes e incisivas, sobre grupos vulnerables o individuos que los integran, amplísimo universo en el espacio americano. Adelante me referiré de nuevo a estos puntos. Esta dedicación natural, que complementa las definiciones progresistas de los derechos y las libertades enunciados por la Convención, concurre a establecer y caracterizar la vocación institucional de una Corte creada para los ciudadanos del "mundo americano", y que hace su propia tarea en la "navegación" --también americana- por los derechos humanos.

ix. El "Juez natural" del Sistema. Permanencia y AUTONOMÍA

29. La CorteIDH ha sido y es un tribunal permanente, si entendemos con rectitud la permanencia como ejercicio ininterrumpido y eficaz de las atribuciones a su cargo, no apenas como reunión constante de los integrantes del Tribunal en torno a una mesa de deliberaciones. El carácter trascendente de su desempeño, en los términos en que lo caracterizo, contribuye a que la Corte pueda atender su vocación y servir a su objetivo en un número relativamente reducido de opiniones y sentencias. Ocurrió en la etapa a la que aludo directamente en este artículo y ha sucedido en las anteriores y posteriores. La trascendencia no deriva de millares de resoluciones 
reiterativas, sino de criterios oportunamente establecidos, con signo justiciero y progresista, a veces calificadas como "paradigmáticas", sobre temas y problemas de gran entidad, que reclaman la atención transformadora a cargo de la jurisprudencia interamericana. Los números son moderados; las decisiones, trascendentales. Hasta junio de 2018, el Tribunal había emitido 24 opiniones consultivas y 352 sentencias en relación con 236 casos contenciosos.

30. La CortelDH es el juez natural en el Sistema que le incumbe. Este es un punto central para su operación, sin riesgo de naufragio o extravío. Recordemos la disposición del Pacto de San José (artículo 8.1), que también se aplica, naturalmente, al Tribunal Interamericano: independencia, imparcialidad y competencia. Estimo que se ha honrado esta regla - un "dogma"-, que constituye un principio inamovible para cualquier verdadero tribunal de justicia. La Corte ha sufrido opiniones encontradas y ha resistido señalamientos adversos, determinados por sentencias justas en contra de situaciones injustas. Creo que nada de esto ha desviado el curso del Tribunal en su compromiso de independencia, imparcialidad y competencia. Lo muestra su enérgica y serena resistencia a ciertos avatares del pasado o del presente, y estoy seguro de que lo mostraría si aquéllos cruzaran de nuevo en su camino.

31. La Corte Interamericana ha operado con recursos escasos. Es preciso incrementar éstos como lo ordenan la razón y múltiples acuerdos, insuficientemente cumplidos, de la Organización de los Estados Americanos y de la Cumbre de las Américas, ${ }^{34}$ incremento constantemente requerido antes, durante y después de mi propia

34 En diversos momentos se ha dispuesto el incremento de las aportaciones destinadas a financiar el Sistema Interamericano de protección de derechos humanos en distintos momentos. Mencionaré sólo algunos ejemplos de esta reiterada disposición, cfr. OEA, Asamblea General, Resolución 1828 (XXXI-O/01), 5 junio 2001, OEA, Asamblea General, Resolución 2908 (XLVII-O/17), 21 de junio de 2017, y Tercera Cumbre de las Américas, Declaración de la ciudad de Québec, 2001, párr. 7. 
etapa judicial. No se desconoce esa insuficiencia inquietante, pero ella no ha detenido la actividad de la Corte ni mermado su desempeño en perjuicio de la vocación institucional que le compete.

\section{Integración del Tribunal: Nueva interpretación}

32. En la etapa de mi desempeño judicial, la Corte tuvo oportunidad de deliberar sobre su integración y de modificar un arraigado criterio interpretativo, que no tuvo el rango de costumbre internacional. Me refiero a la interpretación del artículo 55 CADH sobre participación de jueces ad hoc en la composición del Tribunal y actuación de jueces de la nacionalidad del Estado al que se imputa la violación sujeta a juicio. $\mathrm{Al}$ abordar este asunto debo decir que guardo excelente recuerdo de jueces ad hoc con los que compartí el conocimiento de diversos casos. Pero ahora no invoco experiencias personales, sino me remito a la debida regularidad en la integración de un tribunal y en el despacho de las causas.

33. La Corte acertó en la Opinión Consultiva OC-20/2009-en la que participé-, ponderando el principio de igualdad entre las partes que comparecen ante un tribunal y considerando, con sensibilidad, que los jueces deben ser y además "parecer" independientes e imparciales a la luz de cualquier observación rigurosa, incluso la mirada de las víctimas, de los Estados o de otros analistas calificados. Antes de que se adoptara la bienvenida $O C$-20, me inhibí de intervenir en el conocimiento de casos concernientes al país de mi nacionalidad. ${ }^{35}$ Expuse razones que finalmente transitaron a la jurisprudencia de la Corte.

35 Así, por ejemplo, en el caso Castañeda Gutman vs. México, 6 de agosto de 2008; González y otras ("Campo Algodonero") vs. México, 16 de noviembre de 2009, y Radilla Pacheco vs. México, 23 de noviembre de 2009.

Sobre este tema, señalé que "el buen desempeño de las funciones jurisdiccionales no reposa solamente en la integridad y capacidad del juez -que son indispensables, por supuesto-, sino también en la valoración que se haga sobre aquéllas. 
34. Hoy día, la intervención de jueces ad hoc se confina a los casos interestatales. Así se reconoce el origen de ese personaje en procedimientos ante tribunales que resuelven sobre contiendas entre Estados, no entre éstos y los particulares. Sin embargo, mantengo la reserva que desde hace tiempo expresé sobre la figura del juez ad hoc. Consta en mi voto particular sobre la citada OC-20: "Algunos de los argumentos con los que se cuestiona su intervención en los denominados casos individuales, abonarían su exclusión en la otra categoría". Lo "más razonable sería que el tribunal quedase integrado con jueces que no ostentan la nacionalidad de alguna de las partes. Así el tribunal correspondería, con mayor evidencia, a la figura del tercero colocado fuera y por encima de las partes". ${ }^{36}$

\section{LOS PROTAGONISTAS}

35. Me he referido al órgano jurisdiccional interamericano. Debo comentar otros extremos de lo que he denominado los "protagonistas" del Sistema, dato político-operativo de éste. ${ }^{37}$ En el marco de los protagonistas figuran los Estados, la OEA, las instituciones de la sociedad civil, los órganos internacionales de supervisión -Comisión y Tribunal- y otros sujetos a los que califico como actores "emergentes". ${ }^{38}$ Éstos han llegado a ocupar espacios importantes y a desempeñar papeles cada vez más relevantes en la operación del Sistema. Ahora no puedo extenderme sobre ellos, pero mencionaré

Ser, pero también parecer". Radilla Pacheco vs. México, 23 de noviembre de 2009, p. 1 y <http://www.corteidh.or.cr/docs/casos/articulos/seriec_209_esp.pdf>.

36 Cfr. Votos..., cit., pp. 102 y ss., y <http://www.corteidh.or.cr/docs/opiniones/seriea_20_esp1.pdf>.

37 Sobre los elementos o datos del sistema. Cfr. García Ramírez, La Corte Interamericana..., pp. 57 y ss.

38 Cfr. García Ramírez, Los derechos humanos y la jurisdicción interamericana, México, Porrúa, 2018, p. 202, Votos..., cit., p. 519, y <http://www.corteidh.or.cr/ docs/casos/articulos/seriec_191_esp.pdf>. 
que en las décadas recientes se incrementó su número con la presencia del ombudsman y la defensoría pública, inicialmente vistos con algún recelo por tratarse de órganos del Estado que no podrían militar, para los efectos de la justicia supranacional, en las filas de éste, y tampoco podrían hacerlo - se supuso- en el banco de las víctimas y sus allegados. Por fortuna, esta objeción decayó y titulares del ombudsman y de la defensoría pública interna pudieron atender fuera de sus fronteras territoriales la defensa de los derechos de las víctimas, como lo habían hecho fronteras adentro. Lo vimos en un caso significativo, conocido en el tiempo en que participé en el Tribunal. ${ }^{39}$ Los buenos resultados de esta intervención, que no añadió gramos al platillo del Estado, fortaleció la posición de las víctimas ante la jurisdicción supranacional.

36. El vínculo con las defensorías públicas nacionales animó la antigua propuesta de la Corte para que el Sistema contase con defensores profesionales de las víctimas que no pueden allegarse, por sí mismas, la asistencia jurídica que requieren. Sostuve esta propuesta -como lo hicieron mis antecesores- ante la OEA. Al amparo de útiles iniciativas se estableció una novedosa institución, el Defensor Interamericano, cuyo desempeño se ha apoyado con un Fondo de Asistencia Legal de Víctimas, integrado en el tiempo sobre el que tengo experiencia directa. ${ }^{40}$

39 Durante la audiencia del caso Ticona Estrada y otros vs. Bolivia-celebrada en Montevideo, Uruguay- el Defensor del Pueblo compareció en la representación de las presuntas víctimas. Cfr. Ticona Estrada y otros vs. Bolivia, 27 de noviembre de 2008, párr. 8.

40 El 3 de junio de 2008 la Asamblea General de la OEA aprobó la creación del Fondo de Asistencia Legal del Sistema Interamericano de Derechos Humanos. Cfr. OEA, Asamblea General, Resolución 2426 (XXXVIII-O/08), "Creación del Fondo de Asistencia Legal del Sistema Interamericano de Derechos Humanos", puntos resolutivos 2.d) y 3 . 
XII. DeRechos Y LIBERTADES, TEMAS DE LA JURISPRUdENCIA

37. En un breve artículo panorámico como el presente no es posible aludir a todos los temas abordados por la jurisprudencia de la Corte. Intentaré, sin embargo, una brevísima noticia, considerando que tuve oportunidad de intervenir como juzgador en la formación de opiniones o la solución de casos relativos a los temas que en seguida mencionaré.

38. Desde luego, la jurisprudencia interamericana se ha ocupado en el examen de las obligaciones generales de los Estados y ha caracterizado los deberes de respeto, garantía y adopción de medidas. Debo subrayar aquí los pronunciamientos a propósito del deber de garantía y la obligación de abatir la impunidad -tema muy transitado- y juzgar los actos violatorios bajo el Derecho interno y el Derecho internacional de los derechos humanos. Es bien conocida la jurisprudencia que rechaza medidas cuya consecuencia sea el olvido de las violaciones cometidas y la consecuente impunidad de sus autores. Me pronuncié en este sentido, a través de votos particulares, coincidiendo con mis colegas. ${ }^{41}$ Se ha suscitado una cuestión relevante a propósito de la "justicia transicional" -que adelante mencionaré de nuevo--, tomando en cuenta los diversos escenarios en los que ésta se plantea: secuela de un conflicto interno, que se pretende cerrar, o etapa posterior a la declinación de un gobierno autoritario que incurrió en violaciones de derechos como medio de control político.

39. La Corte fijó criterios importantes para el rechazo a la impunidad y acerca de la responsabilidad internacional del Estado. En tal sentido, analizó la responsabilidad generada por personas o grupos que no pertenecen formalmente al Estado, pero actúan -vul-

41 Cfr. Votos..., cit., pp. 125-128, 151-155, y 461-463, y <http://www.corteid h.or.cr/docs/casos/articulos/seriec_43_esp.pdf>; <http://www.corteidh.or.cr/d ocs/casos/articulos/Seriec_75_esp.pdf> y <http://www.corteidh.or.cr/docs/ca sos/articulos/seriec_162_esp.pdf>. 
nerando derechos fundamentales- merced al apoyo, la tolerancia o la indiferencia de éste. Esta doctrina del Tribunal supranacional se proyecta sobre la responsabilidad internacional del Estado y sobre las fuentes del deber de reparar en diversas vertientes: rectificación de omisiones y reparación de agravios.

40. La Corte ha fijado el alcance de un amplio número de derechos y libertades consagrados en la CADH y en otros instrumentos que debe aplicar o a los que debe recurrir -aunque no los aplique directamente- ${ }^{-}$para fijar los términos del Derecho internacional y orientar, al amparo de éste, sus propias reflexiones y decisiones. En una rápida mirada sobre los derechos analizados por la más frecuente jurisprudencia de la Corte figuran temas de primer orden, que a menudo poseen especial intensidad en el encuentro entre la autoridad y los ciudadanos. Pude intervenir en el examen de la mayoría; otros llegaron al conocimiento de la Corte posteriormente.

41. A título de ejemplos mencionaré algunos temas de la jurisprudencia interamericana, sin internarme en su examen: primado del principio pro persona, que se halla en la base del régimen de interpretación de derechos, libertades y deberes generales; alcance de la titularidad de los derechos humanos en el doble plano de las personas físicas y morales; igualdad y no discriminación, sin olvido del principio de especificidad al que adelante me referiré; reconocimiento de la personalidad jurídica y derecho a la identidad y al nombre; restricciones a la pena capital con firme tendencia abolicionista; ${ }^{42}$ medidas para favorecer la calidad de la vida; integridad física y psicológica; formas contemporáneas de esclavitud; medidas restrictivas o privativas de la libertad; legalidad -naturaleza y alcance de la ley, idea que se proyecta sobre la más importante función reguladora del Estado-; honra y dignidad; dimensiones individual y social de la

42 Mi voto en el caso Raxcacó Reyes, párrs. 1-12. Cfr. Votos..., cit., pp. 344-350, y <http://www.corteidh.or.cr/docs/casos/articulos/seriec_133_esp.pdf>.

También, cfr. CorteIDH, Pena de muerte, Cuadernillos de jurisprudencia de la Corte Interamericana de Derechos Humanos, CorteIDH, 2017. 
libertad de expresión y ejercicio del periodismo, ${ }^{43}$ ámbito en el que expresé claramente mi posición desfavorable al empleo de la vía penal; ${ }^{44}$ asociación; tutela de la familia; protección del niño -tema sobre el que también volveré-; diversas implicaciones del uso y goce de bienes, entraña del derecho a la propiedad privada; participación en las decisiones de la sociedad a la que se pertenece y acceso a la función pública; protección judicial como tutela ordinaria efectiva y como garantía de derechos fundamentales; suspensión del ejercicio de derechos, ${ }^{45}$ y derechos económicos, sociales y culturales, cuya justiciabilidad constituye uno de los temas de mayor relevancia y trascendencia para la jurisdicción interamericana. ${ }^{46}$

43 Cfr. García Ramírez y Alejandra Gonza, Libertad de expresión en la jurisprudencia de la Corte Interamericana de Derechos Humanos, Miami, 4ª ed., Sociedad Interamericana de Prensa, 2016.

También, cfr. CorteIDH, Libertad de pensamiento y expresión, Cuadernillos de jurisprudencia de la Corte Interamericana de Derechos Humanos, CorteIDH, 2017.

44 Así, en mi voto en el caso Kimel. Cfr. Votos..., cit., pp. 503-5-504, y <http:// www.corteidh.or.cr/docs/casos/articulos/seriec_177_esp.pdf>.

45 Cfr. García Ramírez, "Tutela de los derechos en situaciones excepcionales. Debido proceso y cumplimiento de resoluciones", en Varios, Reconciliación y Derecho Procesal. Memoria del Coloquio sobre Reconciliación y Derecho Procesal, Ramiro Bejarano Guzmán, Pablo Moreno Cruz y Marcela Rodríguez Mejía (eds.), Bogotá, Instituto Colombiano de Derecho Procesal/International Association of Procedural Law/ Universidad Externado de Colombia, 2016, pp. 341 y ss.

46 Cfr. García Ramírez, "Protección jurisdiccional de los derechos económicos, sociales y culturales", en Cuestiones Constitucionales, núm. 9, julio-diciembre de 2010, pp. 127-157.

También, cfr. Observatorio de Jurisprudencia Interamericana, Derechos económicos, sociales y culturales, Fundación Diálogo Jurisprudencial Interamericano, Observatorio del Sistema Interamericano de Derechos Humanos, 2010-2016. 
XIII. UnA CUESTIÓN PERMANENTE: ACCESO A LA Justicia Y DEBIDO PROCESO

42. Me interesa destacar que entre los temas muy frecuentemente abordados por el Tribunal de San José figura el acceso a la justicia, vinculado al debido proceso, medio sobresaliente para la defensa y rescate de todos los derechos. Es una cuestión invocada en la casi totalidad de los litigios llevados ante la Corte, como ha ocurrido en el espacio jurisdiccional europeo. Esta materia se halla primordialmente regulada por los artículos 8 y 25 de la Convención Americana, aunque también aparece, por diversos motivos, en otros preceptos: así, artículos 4, 5, 7 y 27. La Corte ha elaborado detallada y sólida doctrina acerca del debido proceso, que podría informar una deseable convención regional sobre la materia.

43. La jurisprudencia interamericana ha puesto en relieve los elementos que caracterizan el debido proceso: ante todo, la garantía de plena defensa de los derechos de quienes intervienen en el litigio. Hay aportaciones notables que conviene tener en cuenta y que aluden a un amplio conjunto de opiniones y casos en cuyo conocimiento intervine. ${ }^{47}$ Entre ellos, las referencias al juez natural -independiente, imparcial y competente--, presupuesto del debido proceso, cuya ausencia invalida inmediatamente el enjuiciamiento y hace innecesario entrar al examen de otras violaciones alegadas por el demandante. ${ }^{48}$ En mérito del juez natural, la Corte acotó la

47 En numerosos votos particulares abordé temas generales y específicos del acceso a la justicia y el debido proceso. Figuran, acompañando al desarrollo de la materia, en mi libro, al que me remito, El debido proceso. Criterios de la jurisprudencia interamericana, México, Porrúa, 2016, pp. 101 y ss. También, cfr. Observatorio de Jurisprudencia Interamericana, Derecho a las garantías judiciales, Fundación Diálogo Jurisprudencial Interamericano, Observatorio del Sistema Interamericano de Derechos Humanos, 2014-2015.

48 En mi voto concurrente a la sentencia del caso Usón Ramírez vs. Venezuela, del 20 de noviembre de 2009, sostuve que la presencia y actuación del juez natural constituye un presupuesto - no sólo un elemento- del debido proceso. Cfr. 
actuación de la justicia militar, frecuentemente utilizada en países americanos, y actualmente excluida para los civiles y concentrada en asuntos que atañen a bienes jurídicos del orden castrense.

44. La jurisprudencia interamericana trasladó a todos los procedimientos las garantías explícitamente asignadas al ámbito penal: aquellas pasan, en lo pertinente, de los supuestos previstos en el artículo 8.2 a los regulados en el 8.1. Igualmente, la jurisprudencia ha extendido apreciablemente las disposiciones del debido proceso para la defensa del justiciable, como ocurrió en la notable Opinión Consultiva OC-16/99, a propósito de la protección consular de los detenidos extranjeros, principalmente cuando éstos afrontan la posibilidad de condena a pena capital. ${ }^{49}$

45. En el mismo ámbito del debido proceso, la Corte agregó a la ponderación del plazo razonable el impacto que el transcurso del tiempo puede tener sobre los derechos del individuo - ponderación que sugerí en mis votos particulares-, ${ }^{50}$ además de otros factores que afectan la razonabilidad, consagrados por la jurisprudencia europea y recogidos por la interamericana. En el examen de los recursos que puede emplear el justiciable, esta jurisprudencia ha destacado imperiosamente la impugnabilidad de las sentencias ante un tribunal superior, que va más allá de la revisión concentrada en puntos de legalidad, como ocurre bajo ciertas formas de casa-

Votos..., cit., pp. 518 y ss., y <http://www.corteidh.or.cr/docs/casos/articulos/ seriec_207_esp.pdf>.

49 Me referí al carácter dinámico y expansivo del debido proceso en el voto concurrente que emití para la Opinión Consultiva OC-16/99, "El derecho a la información sobre la asistencia consular en el marco de las garantías del debido proceso", del 1 de octubre de 1999. Cfr. Votos..., cit., pp. 21 y ss., y <http://www. corteidh.or.cr/docs/opiniones/seriea_16_esp.pdf>.

50 En mi voto para la sentencia del caso López Álvarez vs. Honduras, del 1 de febrero de 2006, propuse la consideración de un nuevo elemento para ponderar la razonabilidad del plazo: "afectación actual que el procedimiento implica para los derechos y deberes -es decir, la situación jurídica-del individuo”. Votos..., cit., p. 338, y <http://www.corteidh.or.cr/docs/casos/articulos/seriec_141_esp.pdf>. 
ción que no permiten el examen amplio de violaciones a derechos fundamentales. ${ }^{51}$

XIV. EL DEBER DE GARANTÍA. IMPUNIDAD Y VIOLACIONES GRAVES

46. En el ejercicio de su función, desplegada sobre hechos consumados en contextos fuertemente autoritarios, el Tribunal supranacional ha examinado la exoneración de sujetos responsables de graves violaciones de derechos humanos. Esto quebranta el deber de garantía, amparando las violaciones con sentencias absolutorias o sumamente benévolas a las que se atribuye autoridad de cosa juzgada. Es evidente que no subsistiría la justicia penal internacional ni se tendría en pie la justicia de derechos humanos si los hechos violatorios quedaran al margen de todo enjuiciamiento posterior, bajo al palio de la cosa juzgada. De ahí que la Corte haya insistido -insistencia de la que participé en varios $\operatorname{casos}^{-52}$ en la ineficacia de ciertos procesos "a modo" y de las sentencias dictadas en ellos: ni aquéllos son verdaderos juicios, ni éstas son genuinas sentencias. En tal virtud, se autoriza la reapertura -o mejor dicho, la apertura- de auténticos procesos.

47. En este sector de consideraciones procede mencionar la jurisprudencia sobre investigación de violaciones graves, concepto sobre el que no hay definiciones unánimemente aceptadas, aunque tales

51 Cfr. mi voto particular correspondiente a la sentencia del 2 de julio de 2004 en el caso Herrera Ulloa vs. Costa Rica, en Votos..., cit., pp. 210 y ss., y <http://www. corteidh.or.cr/docs/casos/articulos/seriec_107_esp.pdf>. Asimismo, cfr. mi artículo "Garantías judiciales: doble instancia y amparo de derechos fundamentales (artículos 8.2.h y 25 CADH)", en Varios, El derecho humanos al debido proceso. Sus dimensiones legal, constitucional y convencional, Carlos Pérez Vázquez (coord.), México, Tirant Lo Blanch, 2014, pp.145-168.

52 Cfr. Votos..., cit., p. 341-343 y 464-465, y en: <http://www.corteidh.or.cr/ docs/casos/articulos/seriec_132_esp.pdf> y <http://www.corteidh.or.cr/docs/ casos/articulos/seriec_162_esp.pdf>. 
violaciones son claramente identificables en el examen cuidadoso de los hechos cuestionados. La Corte Interamericana ha fijado las reglas aplicables a la investigación -utilizando referencias alojadas en la normativa contra las ejecuciones extrajudiciales, la tortura o la desaparición forzada-, cuya indagatoria no puede sujetarse a procedimientos apresurados o ligeros. Se habla de investigación ex officio, no condicionada a la gestión o a la diligencia de las víctimas, inmediata, acuciosa, completa, cumplida por autoridades competentes, comprensiva del contexto. La invocación de reglas contenidas en instrumentos de soft law-como el Protocolo de Estambul-confiere a éstos la fuerza preceptiva indispensable para el buen despacho de la investigación. ${ }^{53}$

48. Las reflexiones y decisiones jurisdiccionales acerca del debido proceso - que constituye una suprema garantía de justicia, atenta a la satisfacción de la sociedad y de la víctima y a la respuesta razonable a la contienda entre quien vulnera derechos y quien es titular de éstos- se proyectan hacia la "justicia transicional", aludida en líneas anteriores. La jurisprudencia interamericana ha insistido en la necesidad perentoria de mantener a salvo los principios y reglas del debido proceso, sin desconocer las otras necesidades que sustentan el concepto mismo de una justicia de transición. En el debate sobre esta materia, tan delicada, se ha sugerido reconocer las diferencias que median y la línea divisoria que debe existir entre la atención indispensable a procesos de paz, para erigir una nueva era democrática, y la consagración de la impunidad en favor de los responsables de graves violaciones de derechos humanos. ${ }^{54}$

53 Cfr. García Ramírez, El debido proceso..., cit., pp. 68-71.

54 Cfr. Humberto A. Sierra Porto, "Los retos jurídicos del proceso de paz colombiano", en Varios, Reconciliación..., cit., pp.79-99, y voto del Juez Diego García-Sayán en el caso Masacres de El Mozote y lugares aledaños, en: <http:/ / corteidh. or.cr/docs/casos/articulos/seriec_252_esp.pdf>. Me he referido a este tema en mi artículo "Justicia transicional y jurisprudencia interamericana", en Varios, Fusticia transicional, Dimaro Agudelo Mejía, Liliana Damaris Pabón Giraldo, Luis 
xv. Justiciabilidad de LOS DESCA

49. La protección jurisdiccional de los DESG o DESGA, como se dice recientemente, es decir, la llamada "justiciabilidad" de esos derechos, requiere un comentario especial. Ha sido diversa la puesta en escena de los derechos económicos, sociales y culturales a través de las grandes declaraciones y los tratados internacionales: aquéllos figuran en la Declaración Americana y en la Declaración Universal, pero su tratamiento se hace por separado en los tratados y pactos mundiales y regionales. En esta separación se refleja el concepto de "generaciones" de derechos humanos, que no entraña jerarquía o preferencias inaceptables, sino diferencias cronológicas o documentales a propósito del ingreso al escenario de los derechos reconocidos.

50. A la Conferencia de San José llegó la pretensión de incluir en la Convención el régimen de los derechos económicos, sociales y culturales. Se hizo notar que la observancia de los derechos humanos deriva de la existencia de condiciones propicias, que el Estado debe aportar. ${ }^{55}$ Sin embargo, estas aspiraciones sólo figuraron en el proyecto de Pacto, que recogió una alusión a los deberes de los Estados en esta materia (artículo 25), pero no prevalecieron en la deliberación y en el acuerdo final de esa Conferencia. El tema se incluyó solamente en un precepto, el artículo 26, bajo el rubro de "Desarrollo progresivo", a reserva de que otro instrumento expusiera el catálogo de aquéllos, como efectivamente ocurrió a través del Protocolo de San Salvador. Empero, éste abre la puerta a una

Orlando Toro Garzón, Mónica María Bustamante Rúa y Orión Vargas Vélez (coords.), Medellín, Universidad de Medellín, 2017.

Igualmente, cfr. CorteIDH, Fusticia Transicional, Cuadernillo de Jurisprudencia de la Corte Interamericana de Derechos Humanos, CorteIDH, 2017.

55 Cfr. "Proyecto de Convención Interamericana sobre Protección de Derechos Humanos" y "Enmiendas al proyecto... presentadas por la Delegación de Guatemala", en Actas y Documentos..., cit., pp. 23 y 107 
justiciabilidad muy limitada: asociación sindical y derecho a la educación.

51. La Corte se ha ocupado de los DESCA en tres vertientes o con tres referencias: asegurar la progresividad y rechazar la regresión de éstos, emprender la tutela de DESCA o de bienes atinentes a éstos a través de la protección de ciertos derechos civiles (por ejemplo: salud, mediante la tutela de la integridad; desarrollo de comunidades indígenas, a través de las implicaciones del uso y el goce de bienes; niñez, mediante una comprensión intensa y extensa de la cláusula sobre derechos del niño expuesta en la CADH, etcétera), y proteger los DESCA directamente por conducto del acceso a la justicia y diversas fórmulas de interpretación de la Declaración Americana y el Pacto de San José, ${ }^{56}$ orientación que se ha abierto paso.

XVi. Vulnerables: JuRisprudencia para los más débiles

52. Señalé que entre los temas relevantes, e incluso característicos y definitorios, de la jurisprudencia interamericana se hallan la tutela de los grupos vulnerables y de los individuos que los integran, y el régimen de las reparaciones por violación de derechos humanos. La atención a los derechos humanos de los grupos vulnerables viene de tiempo atrás: se mostró en la Declaración de Viena, de $1993,{ }^{57}$ y ha persistido en el panorama de los instrumentos internacionales y de la jurisprudencia formada a partir de éstos. En América ese interés eminente se acreditó en decisiones de la Cumbre Judicial Iberoame-

56 Cfr. Votos..., cit., pp. 541-546, y <http://www.corteidh.or.cr/docs/casos/ articulos/seriec_198_esp.pdf>; en la misma línea, mi artículo "Protección jurisdiccional internacional...", cit., pp. 136 y ss. Asimismo, cfr. Lagos del Campo vs. Perú, 31 de agosto de 2017, párrs. 141-156, Trabajadores Cesados de Petroperú y otros vs. Perú, Sentencia de 23 de noviembre de 2017, párrs. 192-193, Poblete Vilches y otros vs. Chile, 8 de marzo de 2018, párrs. 100-105.

57 Declaración y Programa de Acción de Viena, aprobado por la Conferencia Mundial de Derechos Humanos, 25 de junio1993, párrs. 18 y ss. 
ricana correspondientes a las Reglas de Brasilia -y sus precedentespara el acceso a la justicia de personas vulnerables ${ }^{58}$ y al Protocolo de la misma especialidad emitido en Santiago de Chile en 2014. ${ }^{59}$ Se ha dado paso a una especie de Derecho judicial interamericano -uso la expresión con libertad, para fines expositivos-acerca de los sujetos vulnerables.

53. En el manejo de esta materia entran en juego dos principios centrales del Derecho internacional de los derechos humanos, sostenidos por la jurisprudencia interamericana. De una parte, el principio de igualdad y no discriminación, al que la Corte reconoce explícitamente fuerza de jus cogens, como se manifestó en la $O C-18 / 03$, en la que participé, ${ }^{60}$ y de la otra -en mi concepto- un principio de "especificidad" que atiende a la necesidad de establecer con realismo la "igualdad entre los desiguales" para que éstos puedan disponer efectivamente - no sólo discursivamente- de aquélla. ${ }^{61}$ Se pretende alcanzar ese equilibrio entre las proclamaciones del Derecho y las imposiciones de la realidad a través de

58 Reglas de Brasilia sobre Acceso a la Justicia de las Personas en Situación de Vulnerabilidad, 2008, en <http://www.ordenjuridico.gob.mx/TratInt/Derechos\%20Humanos/DH091.pdf>.

59 Protocolo Iberoamericano de Actuación Judicial para Mejorar el Acceso a la Justicia de Personas con Discapacidad, Migrantes, Niñas, Niños, Adolescentes, Comunidades y Pueblos Indígenas, 2014, en <http:// www.cumbrejudicial.org/productos-y-resultados/productos-axiologicos / item/38-protocolo-de-acceso-a-la-justicia-para-personas-y-grupos-vulnerables $>$.

60 Cfr. Votos..., cit., pp. 87 y ss., y <http://www.corteidh.or.cr/docs/opiniones/seriea_18_esp.pdf>.

61 Cfr. García Ramírez, Derechos humanos de los menores de edad: perspectiva de la jurisdicción interamericana, México, UNAM, Instituto de Investigaciones Jurídicas, 2010, p. 56; García Ramírez y Laura Martínez Breña, Presos y prisiones: el sistema penitenciario desde la perspectiva de los derechos humanos, México, Porrúa/Universidad Nacional Autónoma de México, Coordinación de Humanidades, Programa Universitario de Derechos Humanos, 2014, pp. 8-9, y mi voto en el caso Ximenes Lopes, en Votos..., cit., p. 411, y <http://www.corteidh.or.cr/docs/casos/articulos/ Seriec_149_esp.pdf>. 
ciertas providencias de compensación ${ }^{62}$ o tutela diferenciada. ${ }^{63} \mathrm{La}$ jurisprudencia interamericana de estos años - en rigor, la de todo el tiempo, con acento creciente- ha procurado atender la igualdad y la especificidad para generar condiciones de ejercicio genuino de los derechos humanos en un Continente en el que la mayoría de la población podría inscribirse bajo el concepto de vulnerable.

54. El elenco de los grupos o sujetos vulnerables se localiza en la Declaración de 1993 -que ya mencioné- y más puntualmente en las Reglas de Brasilia, por lo que toca al acceso a la justicia. Con sustento en estos documentos es posible analizar la jurisprudencia del Tribunal de San José en materia de derechos de mujeres, niños, indígenas, personas en situación de pobreza, personas con discapacidad, migrantes, desplazados y sujetos privados de libertad. Es pertinente incluir otras categorías que también ha examinado la Corte con un criterio tutelar específico atento a la vulnerabilidad de sus componentes, probada ante el Tribunal: así, los integrantes de las comunidades LGBTI, los periodistas y los defensores de derechos humanos. Aquellos constituyen una minoría bajo asedio, recientemente movilizada para el rescate de sus derechos; los segundos militan en profesiones o actividades que se hallan en grave riesgo determinado por el enrarecimiento de la observancia de los derechos humanos.

55. En la jurisprudencia de los años en que integré o presidí el Tribunal, hubo progreso en la atención a las mujeres, es decir, en la aplicación de la "perspectiva de género", que informa grandes tratados internacionales: CEDAW, de Naciones Unidas, esforzada contra la discriminación, y Belém do Pará (1994), del Sistema Interamericano, dirigida contra la violencia. La primera decisión de la Corte que aplicó directamente la Convención de Belém do Pará

62 Eduardo J. Couture, Estudios de Derecho Procesal Civil, Buenos Aires, Depalma, 1978, tomo I, pp. 275-276

63 Roberto Berizonce, Las tutelas procesales diferenciadas, Buenos Aires, Rubinzal-Gulzoni, 2009. 
fue la sentencia sobre el caso del penal Castro Castro. En el voto particular que emití entonces expuse los argumentos de carácter sustantivo y procesal que sustentan la competencia material de la CorteIDH para la aplicación directa de la Convención de Belém. ${ }^{64}$ Luego llegarían varias sentencias en la misma línea, considerablemente enriquecida.

56. Por lo que toca a niños, niñas y adolescentes, o bien, menores de edad - una vez superado el debate terminológico-, también hubo y sigue habiendo pronunciamientos relevantes. Destaca la Opinión Consultiva OC-17/02, solicitada por la Comisión Interamericana a propósito de cuestiones procesales, pero comprensiva de otras manifestaciones del trato del Estado -y diversos sujetos obligados- con respecto a los niños, las niñas y los adolescentes. ${ }^{65}$ El Tribunal de San José destacó el interés superior del niño, que diversos instrumentos exaltan, y su condición como titular de derechos, no sólo destinatario de la protección del Estado. Igualmente, la $O C-17$ se refirió al carácter especial de garante que incumbe al Estado en su trato con menores de edad, y también con otros sujetos vulnerables. En el célebre caso Niños de la Calle (1997) el Tribunal estudió -con reflexiones innovadoras en el ámbito de su jurisprudencia- la protección del derecho a la vida, no sólo a través de abstenciones, sino mediante acciones positivas que aseguren una vida digna.

64 Mi punto de vista sobre la competencia de la Corte Interamericana para aplicar directamente la Convención de Belém do Pará figura en el voto que emití con respecto a la sentencia de fondo, reparaciones y costas del caso Miguel Castro y Castro vs. Perú del 25 de noviembre de 2006, en Votos..., cit., pp. 390 y ss., y <http:/ / www.corteidh.or.cr/docs/casos/articulos/seriec_160_esp.pdf $>$.

65 El voto que emití en relación con la Opinión Consultiva OC-17/02, "Condición jurídica y derechos humanos del niño" - en el que igualmente analizo la superable antinomia entre las versiones "tutelar" y "garantista" acerca del procedimiento aplicable a los niños y adolescentes en conflicto con la ley penal- aparece en Votos..., cit., pp. 24 y ss., y <http://www.corteidh.or.cr/docs/opiniones/ seriea_17_esp.pdf>. Cfr., asimismo, García Ramírez, Derechos humanos de..., cit., pp. 99 y ss. 
57. La jurisprudencia de la Corte sobre derechos de indígenas - un sector de gran importancia histórica y actual en el mundo americano, donde también tienen presencia otros grupos étnicos vulnerables: afrodescendientes- cobró mayor vuelo en el examen del caso Mayagna, del año 2000. Recuerdo el análisis que los magistrados hicimos acerca de la vinculación especial de los pueblos indígenas con la tierra -o los territorios- que han ocupado tradicionalmente, y las consecuencias jurídicas de esa vinculación, así como la observancia de los usos y costumbres al amparo del Derecho internacional, que confiere un marco normativo sui generis a las comunidades indígenas. De ese examen data la reflexión en tomo a la necesidad de apreciar los derechos de los individuos en conexión con los derechos de las comunidades a las que aquéllos pertenecen, posibilidad que subrayé en el análisis de los artículos 1.2 y $21 \mathrm{CADH} .{ }^{66}$

58. El Sistema Interamericano emitió una convención sobre personas que presentan alguna forma de discapacidad, antes de que lo hiciera el Sistema Mundial. En su jurisprudencia, la Corte acentuó los deberes del Estado en hipótesis de delegación o subrogación en manos de particulares de medidas curativas o asistenciales, originalmente atribuidas al poder público. ${ }^{67}$ En pos de esas reflexiones, el Tribunal ha formulado decisiones que aluden a la situación de las personas con discapacidad y, más ampliamente, a enfermos o personas que padecen ciertas restricciones o limitaciones cuya superación amerita medidas especiales; tal ha sido el caso de la fecundación in vitro, tema que examinó el Tribunal de San José - con posterioridad

66 Este voto, vinculado a la sentencia de la CorteIDH en el caso Comunidad Mayagna (Sumo) Awas Tingni vs. Nicaragua, del 31 de agosto de 2001, aparece en Votos..., cit., pp. 113 y ss., y <http://www.corteidh.or.cr/docs/casos/articulos/ Seriec_79_esp.pdf>.

67 Cfr. mi examen de esta materia en el voto del caso Ximenes Lopes vs. Brasil en Votos..., cit., pp. 363 y ss., y <http://www.corteidh.or.cr/docs/casos/articulos/ Seriec_149_esp.pdf>. 
a la etapa de mi desempeño judicial-, entendiendo que la infertilidad es una manifestación especial de discapacidad.

59. Se ha hecho notar que la pobreza, extremada bajo la forma de indigencia, constituye un obstáculo -en ocasiones irremontablepara el efectivo ejercicio de los derechos humanos. Esta cuestión también ha ocupado a la Corte, que produjo criterios favorecedores del acceso a la justicia de quienes carecen de los medios necesarios para obtener una tutela efectiva.

60. La migración ofrece características específicas en el espacio americano, además de las muy graves que tiene en el ámbito mundial, últimamente agudizadas por adversas condiciones de vida en lugares donde imperan la pobreza, la violencia o el rezago económico y laboral. La situación de los extranjeros en países de recepción o tránsito, trátese de migrantes regulares o de migrantes indocumentados, ha sido un tema de atención principal en la jurisprudencia interamericana, en la que tuve oportunidad de participar. ${ }^{68}$ Ésta se ha pronunciado en opiniones consultivas, sentencias sobre casos contenciosos y medidas provisionales, destacando invariablemente el primado de los derechos humanos de quienes migran o lo intentan, sobre cualesquiera disposiciones o políticas nacionales que pudieran entrañar menoscabo de aquéllos. En la misma línea figura la jurisprudencia reciente a propósito de los desplazamientos forzados -internos o internacionales-, que implican violación a diversos derechos.

61. La situación de los reclusorios en países americanos es deplorable, inadmisible; trae consigo la violación sistemática y masiva de diversos derechos en agravio de individuos o grupos numerosos. La prisión se aplica en demasía, casi siempre en condiciones sumamente desfavorables. En esta situación operan muchos reclusorios, a título de "instituciones totales": la vida se halla minuciosamente

68 Cfr. Votos..., cit., pp. 86 y ss., y <http://www.corteidh.or.cr/docs/opiniones /seriea_18_esp.pdf>. 
regulada y controlada; o bien, a la inversa, prevalece el desorden e impera la ley de la selva. ${ }^{69}$

62. La jurisprudencia en torno a sujetos privados de libertad no abarca solamente la privación determinada por motivos penales o relacionados con éstos, sino cualesquiera otras formas de privación de libertad dispuesta por el Estado. Empero, las condiciones de vida son especialmente deplorables en los reclusorios donde se desarrolla la prisión preventiva y se ejecuta la punitiva. La jurisprudencia interamericana sobre las medidas que es preciso adoptar con respecto a la detención y al uso de reclusorios ha sido abundante desde el principio y constante a través de los años, tanto acerca de casos individuales como de comunidades de reclusos. La Corte llamó la atención de la Organización de los Estados Americanos acerca de las pésimas condiciones de vida prevalecientes en los reclusorios de nuestra región. Lo hice como Presidente del Tribunal, en informe ante la OEA. ${ }^{70}$

63. La tutela jurisdiccional de los vulnerables, al amparo de la CorteIDH, se ha extendido hacia otros grupos o individuos que han quedado sujetos al asedio de regímenes autoritarios o de presiones tradicionales en el interior de la sociedad, que implican discriminación y lesión. Los practicantes de ciertas profesiones o actividades y

69 Sobre la situación de los reclusorios y la normativa internacional de los derechos humanos aplicable a los reclusos, cfr. García Ramírez y Martínez Breña, Presos y prisiones..., cit., pp. 77 y ss.

70 Ahí señalé que: “(e)n diversos casos se ha observado que existe una verdadera crisis en el sistema de reclusorios para adultos y menores de edad. Esta crisis se traduce en extremada violencia y genera riesgos constantemente señalados. La Corte ha dictado resoluciones sobre medidas provisionales en las que se formulan diversas observaciones a este respecto y se urge a las autoridades a revisar a fondo el sistema de reclusorios. Parece indispensable que la Organización y los Estados dediquen especial atención al examen de este problema y provean soluciones inmediatas y progresivas, según las circunstancias". Consejo Permanente de la OEA, Comisión de Asuntos Jurídicos y Políticos, Sintesis del Informe Anual de la Corte Interamericana de Derechos Humanos correspondiente al ejercicio de 2005, 16 de marzo de 2006, OEA/Ser.G, CP/CAJP-2344/06, pp.18-19. 
los integrantes de diversos grupos han resentido ese asedio y requerido la tutela de la jurisdicción interamericana: miembros de la comunidad LGBTTI, periodistas y defensores de derechos humanos.

XVII. URGENCIA Y GRAVEDAD: MEDIDAS PROVISIONALES

64. Las medidas provisionales, que atienden a la que he llamado "competencia preventiva" de la Corte Interamericana, tuvieron y tienen un importante desarrollo en la jurisprudencia del Tribunal. Éste ha perfilado los fundamentos de las medidas y previsto su permanencia mientras se mantengan las condiciones que las determinaron. Es relevante el criterio establecido por la Corte -que tengo presente por haberse dispuesto y caracterizado en los años en que forme parte de aquélla- para modificar criterios previos y extender las medidas a personas no identificadas que se hallasen en la misma situación -es decir, en "comunidad de riesgo"-que se advirtió con respecto a personas individualizadas. ${ }^{71}$

xvili. Consecuencias jurídicas (reparación): actuar SOBRE LOS FACTORES DE LAS VIOLACIONES

65. Dije que la regulación de las reparaciones constituye un tema sobresaliente de la jurisprudencia interamericana. Ha destacado en poco tiempo, sentencia a sentencia, a través de disposiciones y orientaciones novedosas, con signo "transformador", que acreditan el empeño puesto en esta materia por los autores de la Convención Americana. En este punto, la $\mathrm{CADH}$ se distanció de los criterios adoptados por el Sistema Europeo y de los proyectos que informaron, antes de la Conferencia de 1969, lo que sería el Pacto de

71 Cfr. mi voto conjunto con el juez Alirio Abreu Burelli referente a la resolución del 24 de noviembre de 2000 sobre el Asunto de la Comunidad de Paz de San fosé de Apartadó, en García Ramírez, Votos..., cit., pp. 529 y ss., y < http://www.corteidh. or.cr/docs/medidas/apartado_se_02.pdf>. 
San José. Se ha dicho con razón, a mi juicio, que las aportaciones en materia de consecuencias jurídicas de los hechos violatorios de derechos humanos constituyen la "joya de la corona" en la jurisprudencia interamericana.

66. Tempranamente, la Corte resolvió reorientar el examen de esta materia y superó la noción de "indemnizaciones compensatorias" por la de "reparaciones" en sentido amplio. Luego llegaría -y no ha cesado- la elaboración del régimen plenario de las reparaciones a través de medidas numerosas y diversas que atienden a la fuente de las violaciones e implican corrección consecuente con el carácter de aquéllas y con la necesidad de prevenir violaciones futuras. Pude observarlo y contribuir a ese curso durante mi ejercicio como integrante del Tribunal.

67. Este diseño aportado por la Corte al régimen que ahora menciono condujo a construir un catálogo de medidas de reparación en el que figura -además de las tradicionales indemnizaciones en favor de la víctima o de sus allegados, por daño material o inmaterial, pretérito o futuro- una relación muy amplia de actos públicos de distinta naturaleza: emisión o supresión de normas de cualquier rango -constitucionales, inclusive--, variación de jurisprudencia, invalidación y reapertura de procedimientos judiciales (cosa que entraña la revisión de antiguos conceptos a propósito de la cosa juzgada y el principio ne bis in idem), adopción o modificación de políticas públicas, medidas políticas, económicos o sociales diversas, reconocimiento de responsabilidad del Estado y otras más, que ya integran un conjunto muy variado, siempre dinámico. Desde luego, esta saludable complejidad de las condenas, muy por encima de las compensaciones pecuniarias, se proyecta en el tiempo y en la forma del cumplimiento. ${ }^{72}$

72 He dedicado diversos textos al examen del régimen de reparaciones en la jurisprudencia de la Corte Interamericana, que ciertamente constituye una cuestión de la más elevada importancia, a la que el Tribunal ha incorporado novedades relevantes. Mis puntos de vista en torno a este tema, con el correspondiente deslinde entre las corrientes europea y americana, se expone en García Ramírez 
XiX. Cumplimiento, impacto Y TRASCENDENCIA

68. Acabo de mencionar el cumplimiento de las sentencias, y en otro lugar me referí a la diferencia entre cumplimiento, impacto y trascendencia de la jurisprudencia interamericana. Es importante insistir sobre este último concepto -la trascendencia- que he mencionado varias veces en líneas precedentes y que ahora deseo acentuar, porque se trata de un punto sobresaliente en el desarrollo de la justicia interamericana, dato "clave" para su proyección en el futuro.

69. El Sistema Interamericano no dispone de órganos y procedimientos semejantes a los que forman parte del Sistema Europeo, que se vale, con destacada relevancia, de un mecanismo depositado en los Ministros de los Estados parte en el Convenio de 1950. Tampoco ha corrido con fortuna la idea de instituir un régimen de características similares a aquél, como lo sugirieron mis antecesores y lo mencioné yo mismo en intervenciones en la OEA. ${ }^{73}$ En fin de cuentas, la Corte ha construido un régimen propio, a partir de las normas convencionales y de la interpretación de éstas, considerando asimismo las condiciones de la región y los problemas que suscita el cumplimiento simple y espontáneo de las decisiones supranacionales.

70. La Corte se ha valido de lo que denomino "competencia ejecutiva" para intervenir indagatoriamente en la etapa de cumplimiento nacional de aquellas decisiones. Sostuvo su facultad de requerir a los Estados información puntual y regular sobre la ejecución de las determinaciones jurisdiccionales, atribución que fue

y Marcela Benavides, Reparaciones por violación de derechos humanos. Furisprudencia interamericana, Porrúa, 2014.

73 Cfr. Consejo Permanente de la Organización de los Estados Americanos, Comisión de Asuntos Jurídicos y Políticos, Síntesis del Informe anual de la Corte Interamericana de Derechos Humanos correspondiente al ejercicio del año 2004, OEA/Ser.G, GP/ CAJP/INF.19/05, 10 mayo 2005, p. 11. 
paulatinamente admitida por los Estados y alentada por la OEA. A partir de esta atribución, la Corte estableció en 2007 -en la etapa final de mi desempeño como Presidente- la práctica de convocar a sesiones de revisión de cumplimiento en las que participan los Estados, los beneficiarios de la sentencia (con la calidad de víctimas o allegados a éstas) y la Comisión Interamericana. ${ }^{74}$ Esta práctica, ya prevista en el Reglamento (artículo 69, bajo la reforma de 2009), ha cobrado intensidad y mostrado utilidad. Al cabo de las sesiones - para la supervisión de cumplimiento, privadas o públicas, que pueden versar sobre una sola sentencia o acerca de varias analizadas conjuntamente-, el Tribunal de San José dicta resoluciones en las que menciona el grado de ejecución de las sentencias que motivaron la revisión, señala el punto al que se ha llegado y advierte sobre las medidas pendientes para el cabal cumplimiento de la condena.

\section{Fuentes}

\section{Bibliografía}

Ayala Corao, Carlos, Del diálogo jurisprudencial al control de convencionalidad, Caracas, 2012.

BAZÁn, Víctor, "Estimulando sinergias: de diálogos jurisprudenciales y control de convencionalidad", en Varios, El control difuso de convencionalidad. Diálogo entre la Corte Interamericana de Derechos Humanos y los jueces nacionales, Ferrer Mac-Gregor Poisot, Eduardo (coord.), México, FUNDAP, 2012.

Berizonce, Roberto, Las tutelas procesales diferenciadas, Buenos Aires, Rubinzal-Culzoni, 2009.

Brewer-Garías, Allan R. y Jaime Orlando Santofimio Gamboa, Control de convencionalidad y responsabilidad del Estado, Bogotá, Universidad Externado de Colombia, 2013.

74 Cfr. Corte IDH, Informe anual 2007, pp. 41 y ss., y Baena Ricardo y otros vs. Panamá, Competencia, 28 de noviembre de 2003, párr. 48 y ss. 
Buergenthal, Thomas y Douglass Cassel, "The future of the Interamerican Human Rights System", en Varios, El futuro del Sistema Interamericano de Protección de los Derechos Humanos, Méndez, Juan E. y Cox, Francisco (eds.), San José, Instituto Interamericano de Derechos Humanos, 1998.

Caballero Ochoa, José Luis, La interpretación conforme. El modelo constitucional ante los tratados internacionales sobre derechos humanos y el control de convencionalidad, México, Porrúa, 2013.

Corte Interamericana de Derechos Humanos, Memoria de la Instalación, Secretaría de la CorteIDH/Unión Europea, San José, 1999.

- Informe anual 2007.

- Documentos básicos en materia de derechos humanos en el Sistema Interamericano (actualizado a febrero de 2010), Secretaría de la CorteIDH, San José, 2010.

— Pena de muerte, Cuadernillos de jurisprudencia de la Corte Interamericana de Derechos Humanos, CorteIDH, 2017.

- Libertad de pensamiento y expresión, Cuadernillos de jurisprudencia de la Corte Interamericana de Derechos Humanos, CorteIDH, 2017.

—, Fusticia Transicional, Guadernillos de Jurisprudencia de la Corte Interamericana de Derechos Humanos, CorteIDH, 2017.

—, voto del Juez Diego García-Sayán en el caso Masacres de El Mozote y lugares aledaños.

Couture, Eduardo J., Estudios de Derecho Procesal Civil, Buenos Aires, Depalma, 1978, tomo I.

Ferrer Mac-Gregor Poisot, Eduardo, "Interpretación conforme y control difuso de convencionalidad. El nuevo paradigma para el juez mexicano", en Varios, El control difuso de convencionalidad. Diálogo entre la Corte Interamericana de Derechos Humanos y los jueces nacionales, Ferrer Mac-Gregor Poisot, Eduardo (coord.), México, FUNDAP, 2012.

García Bauer, Carlos, Los derechos humanos. Preocupación universal, Guatemala, Universidad de San Carlos, 1960. 
García Ramírez, Sergio, Estudios jurídicos, México, UNAM, Instituto de Investigaciones Jurídicas, 2000.

—- Temas de derecho, México, Universidad Autónoma del Estado de México/Seminario de Cultura Mexicana/UNAM, Instituto de Investigaciones Jurídicas, 2002.

— Derechos humanos de los menores de edad: perspectiva de la jurisdicción interamericana, México, UNAM, Instituto de Investigaciones Jurídicas, 2010.

— L L Corte Interamericana de Derechos Humanos, 2ª ed., México, Porrúa, 2015.

- Votos particulares en la Corte Interamericana de Derechos Humanos y reflexiones sobre el control de convencionalidad, $2^{a}$. ed., México, GNDH, 2015.

— El debido proceso. Criterios de la jurisprudencia interamericana, México, Porrúa, 2016.

- Los derechos humanos y la jurisdicción interamericana, México, Porrúa, 2018.

_- "Una controversia sobre la competencia de la Corte Interamericana de Derechos Humanos", en García Ramírez, La jurisdicción internacional. Derechos humanos y justicia penal, México, Porrúa, 2003.

__ , "La navegación americana de los derechos humanos: hacia un ius commune", en Varios, Ius constitutionale commune en América Latina. Rasgos, potencialidades y desafios, Armin von Bogdandy, Héctor Fix-Fierro y Mariela Morales Antoniazzi (coords.), México, Instituto Max Planck/UNAM, Instituto de Investigaciones Jurídicas, 2014.

—_, "Garantías judiciales: doble instancia y amparo de derechos fundamentales (artículos 8.2.h y $25 \mathrm{CADH}$ )", en Varios, El derecho humanos al debido proceso. Sus dimensiones legal, constitucional y convencional, Carlos Pérez Vázquez (coord.), México, Tirant Lo Blanch, 2014. 
—_, "Tutela de los derechos en situaciones excepcionales. Debido proceso y cumplimiento de resoluciones", en Varios, Reconciliación y Derecho Procesal. Memoria del Coloquio sobre Reconciliación y Derecho Procesal, Ramiro Bejarano Guzmán, Pablo Moreno Cruz y Marcela Rodríguez Mejía (eds.), Bogotá, Instituto Colombiano de Derecho Procesal/International Association of Procedural Law/Universidad Externado de Colombia, 2016.

—_, "Justicia transicional y jurisprudencia interamericana", en Varios, Fusticia transicional, Dimaro Agudelo Mejía, Liliana Damaris Pabón Giraldo, Luis Orlando Toro Garzón, Mónica María Bustamante Rúa y Orión Vargas Vélez (coords.), Medellín, Universidad de Medellín, 2017.

—_ y Laura Martínez Breña, Presos y prisiones: el sistema penitenciario desde la perspectiva de los derechos humanos, México, Porrúa/Universidad Nacional Autónoma de México, Coordinación de Humanidades, Programa Universitario de Derechos Humanos, 2014.

_- y Marcela Benavides, Reparaciones por violación de derechos humanos. Furisprudencia interamericana, Porrúa, 2014.

— - y Alejandra Gonza, Libertad de expresión en la jurisprudencia de la Corte Interamericana de Derechos Humanos, Miami, $4^{\mathrm{a}}$. ed., Sociedad Interamericana de Prensa, 2016.

— y Zanghi, Claudio, "Las jurisdicciones regionales de derechos humanos y las reparaciones y efectos de las sentencias", en Varios, El diálogo entre los sistemas europeo y americano de derechos humanos, Raúl Canosa Usera, Javier García Roca, Pablo Santolaya y Pablo Antonio Fernández (coords.), 2a .ed., Lima, Thomson Reuters, 2015.

González Morales, Felipe, Sistema Interamericano de Derechos Humanos, Valencia, Tirant lo Blanch, 2013.

Observatorio de Jurisprudencia Interamericana, Derechos económicos, sociales y culturales, Fundación Diálogo Jurisprudencial Interamericano, Observatorio del Sistema Interamericano de Derechos Humanos, 2010-2016. 
——, Derecho a las garantías judiciales, Fundación Diálogo Jurisprudencial Interamericano, Observatorio del Sistema Interamericano de Derechos Humanos, 2014-2015.

Organización de los Estados Americanos, Conferencia Especializada Interamericana sobre Derechos Humanos, San José, Costa Rica, 7-22 de noviembre de 1969, Actas y Documentos, Secretaría General, Washington, D.C., rep. 1978.

Rey Cantor, Ernesto, Control de convencionalidad de las leyes y derechos humanos, México, Porrúa, 2008.

Rosales, Emmanuel, "En busca del acorde perdido o la necesidad de un lenguaje común para el análisis sistemático de la aplicación del Derecho internacional de derechos humanos por cortes nacionales", en Varios, El control de convencionalidad y las cortes nacionales. La perspectiva de los jueces mexicanos, García Villegas Sánchez Cordero, Paula M. (coord.), México, Porrúa, 2013.

SaAvedra, Pablo y Gabriela Pacheco Arias, "Las sesiones 'itinerantes' de la Corte Interamericana de Derechos Humanos: un largo y fecundo caminar por América", en Varios, Recepción nacional del Derecho internacional de los derechos humanos y admisión de la competencia contenciosa de la Corte Interamericana, García Ramírez, Sergio y Castañeda, Mireya (coords.), México, Secretaría de Relaciones Exteriores/ UNAM, Instituto de Investigaciones Jurídicas, 2009.

Sagüés, Néstor Pedro, La interpretación judicial de la Constitución. De la constitución nacional a la constitución convencionalizada, México, Porrúa, 2013.

—_ La Constitución bajo tensión, Querétaro, Instituto de Estudios Constitucionales, 2016.

—_, "El control de convencionalidad como instrumento para la elaboración de un ius commune interamericano", en Varios, La justicia constitucionaly su internacionalización. ¿Hacia un ius constitucionale commune en América Latina?, Bogdandy, Armin von, Ferrer Mac-Gregor Poisot, Eduardo y Morales Antoniazzi, Mariela (coords.), México, UNAM, Instituto de Investigaciones Jurídicas/ Instituto Max Planck/ Instituto Iberoamericano de Derecho Constitucional, t. II, 2010. 
- "El control de convencionalidad en el Sistema Interamericano y sus anticipos en el ámbito de los derechos económico-sociales. Concordancias y diferencias con el Sistema Europeo", en Varios, El control difuso de convencionalidad. Diálogo entre la Corte Interamericana de Derechos Humanos y los jueces nacionales, Ferrer Mac-Gregor Poisot, Eduardo (coord.), México, FUNDAP, 2012.

Sierra Porto, Humberto A., "Los retos jurídicos del proceso de paz colombiano", Varios, Reconciliación y Derecho Procesal. Memoria del Coloquio sobre Reconciliación y Derecho Procesal, Bejarano Guzmán, Ramiro, Moreno Cruz, Pablo y Rodríguez Mejía, Marcela (eds.), Bogotá, Instituto Colombiano de Derecho Procesal/International Association of Procedural Law/Universidad Externado de Colombia, 2016.

Torres Bodet, Jaime, La victoria sin alas, México, Fundación Miguel Alemán, 2012.

Úbeda de Torres, Amaya, Democracia y derechos humanos en Europa y en América. Estudio de los sistemas europeo e interamericano de protección de los derechos humanos, Madrid, Reus, 2007.

VArios, Eficacia del Sistema Interamericano de Derechos Humanos, Bogotá, Universidad Católica de Colombia, 2015

VArios, La Corte Interamericana de Derechos Humanos. Un cuarto de siglo: 19792004, CorteIDH, San José, 2005.

Vergottini, Giuseppe de, Más allá del diálogo entre tribunales, comparación y relación entre jurisdicciones, trad. de Pedro J. Tenorio Sánchez, Pamplona, Civitas-Thomson Reuters, 2010.

\section{Hemerografía}

García Ramírez, Sergio, "Protección jurisdiccional de los derechos económicos, sociales y culturales", en Cuestiones Constitucionales, núm. 9, julio-diciembre de 2010.

Hitters, Juan Carlos, "Control de constitucionalidad y control de convencionalidad. Comparación”, en La Ley, Buenos Aires, 2009, pp. 1-5. 
3. Otros

Consejo Permanente de la Organización de los Estados Americanos, Comisión de Asuntos Jurídicos y Políticos, Sintesis del Informe Anual de la Corte Interamericana de Derechos Humanos correspondiente al ejercicio del año 2004, OEA/Ser.G, CP/CAJP/INF.19/05, 10 mayo 2005.

— - Sintesis del Informe Anual de la Corte Interamericana de Derechos Humanos correspondiente al ejercicio de 2005, 16 de marzo de 2006, OEA/Ser.G, CP/CAJP-2344/06.

CorteIDH, Baena Ricardo y otros vs. Panamá, Competencia, 28 de noviembre de 2003.

—- Almonacid Arellano y otros vs. Chile, 26 de septiembre de 2006.

—, Castañeda Gutman vs. México, 6 de agosto de 2008.

—, Bulacio vs. Argentina, Supervisión de Cumplimiento de Sentencia, Resolución de la Corte Interamericana de Derechos Humanos de 26 de noviembre de 2008.

—, González y otras ("Campo Algodonero") vs. México, 16 de noviembre de 2009.

_ Radilla Pacheco vs. México, 23 de noviembre de 2009.

—, Gomes Lund y otros ("Guerrilha do Araguaia") vs. Brasil, 24 de noviembre de 2010 .

—- Cabrera García y Montiel Flores vs. México, 26 de noviembre de 2010.

—. Lagos del Campo vs. Perú, 31 de agosto de 2017.

—, Trabajadores Cesados de Petroperú y otros vs. Perú, Sentencia de 23 de noviembre de 2017.

- Poblete Vilches y otros vs. Chile, 8 de marzo de 2018.

Corte Suprema de Justicia de la Nación (Argentina), Espósito, Miguel Ángel s/ incidente de prescripción de la acción penal promovido por su defensa, 23 de diciembre de 2004.

Conferencia Mundial de Derechos Humanos, Declaración y Programa de Acción de Viena, 25 de junio1993,

OEa, Asamblea General, Resolución 1828 (XXXI-O/01), 5 junio 2001. 
—, Resolución 2426 (XXXVIII-O/08), "Creación del Fondo de Asistencia Legal del Sistema Interamericano de Derechos Humanos".

—, Resolución 2908 (XLVII-O/17), 21 de junio de 2017.

Gumbre Judicial Iberoamericana, Protocolo Iberoamericano de Actuación Judicial para Mejorar el Acceso a la Justicia de Personas con Discapacidad, Migrantes, Niñas, Niños, Adolescentes, Comunidades y Pueblos Indígenas, 2014.

— Reglas de Brasilia sobre Acceso a la Justicia de las Personas en Situación de Vulnerabilidad, 2008.

Tercera Gumbre de las Américas, Declaración de la ciudad de Québec, 2001. 